\title{
Encephalopathy Associated with Psychotropic Drug Therapy
}

\author{
Yuji Odagaki \\ Department of Psychiatry, Faculty of Medicine, Saitama Medical University \\ Department of Psychiatry, Moro Hospital
}

Japan

\section{Introduction}

All therapeutic interventions are double-edged swords with benefits and adverse effects, and pharmacotherapy is not an exception. Shortly after the introduction of conventional antipsychotic drugs into clinical practice, relatively rare but serious complications with hyperthermia, muscle rigidity, autonomic instability, and disturbed mental status were recognized to develop in some patients treated with antipsychotics. This type of encephalopathy induced by the use of antipsychotics was referred to as neuroleptic malignant syndrome (NMS), and almost all physicians prescribing antipsychotics are nowadays aware of this adverse phenomenon. Another well-known type of encephalopathy associated with psychotropic drug therapy is serotonin toxicity (ST) or serotonin syndrome (SS), which is characterized by autonomic and neuromuscular symptoms and altered mental status. In contrast with the idiosyncratic nature of NMS, ST is a spectrum pathophysiological state assumed to derive from excess serotonergic neural transmission caused by serotonin-related psychotropic agents. In these two decades, pharmacotherapy with psychotropic drugs for mentally ill patients has been dramatically changed, and classical prototypal antipsychotics and antidepressants have been replaced with atypical antipsychotics and selective serotonin reuptake inhibitors (SSRIs), respectively. These newly developed psychotropic drugs are generally safer and more tolerable than older drugs. However, atypical antipsychotics are not free of the risk of development of NMS, and the explosive prevalence of SSRIs prescribed not only for depression but also for a number of psychiatric diagnoses such as anxiety, eating, impulse-control, and personality disorders may increase the incidence of ST. Therefore, these two pathological states still remain as major adverse effects of psychotropic drugs involving altered functioning of the central nervous system (CNS), to which all clinicians prescribing psychoactive drugs should pay attention. The popularity of SSRIs also increased the case reports of patients suffering from discontinuation syndrome, which sometimes includes CNS symptoms like anxiety and irritability. In this chapter, the author provides a comprehensive overview of the abovementioned adverse effects affecting the CNS function associated with psychotropic pharmacotherapy. In addition, several other pathological conditions potentially causing encephalopathic symptoms in psychiatric patients treated with psychotropic drugs, e.g., hyponatremia, valproate-induced hyperammonemia, transient splenial lesion of the corpus callosum, and so on, are also described. 


\section{Neuroleptic malignant syndrome}

\subsection{Historical background}

In the late 1950s, immediately after the introduction of antipsychotics into the clinical practice, single case reports of encephalopathic reaction to antipsychotic agents with fever, muscle rigidity, and autonomic dysfunction were already described (Kinross-Wright, 1958; Preston, 1959). In 1960s, French psychiatrists took notice of such cases and designated them as NMS (Delay \& Deniker, 1968). However, the syndrome had been thereafter reported only occasionally and little attention had been paid to the concept of NMS, especially in the United States, until Caroff (1980) reviewed 60 cases of NMS reported in the scientific literature to that time. His review article renewed interest of clinicians and researchers all over the world and proliferated the reports on the epidemiology, risk factors, symptomatology, diagnostic criteria, differential diagnoses, pathophysiology, and treatment of the syndrome. At the present time, NMS is one of the most popularly recognized complications of psychotropic pharmacotherapy and described in most standard medical textbooks.

\subsection{Epidemiology}

Along with an increase in awareness of its concept after the Caroff's review (1980), many patients diagnosed as NMS were reported throughout the world and it was recognized that NMS was not so rare than formerly supposed. In the review by Keck et al. (1991) on the epidemiology of NMS, the estimated frequency of NMS was reported to be within a wide range from $0.02 \%$ to $2.4 \%$. The high incidence of NMS reported in earlier studies from the United States is, however, evidently overestimated due to a variety of factors, e.g., retrospective study design, loose diagnostic criteria, adherence to an amorphous "spectrum concept", and clinical practices in vogue (Adityanjee et al., 1999a). Based on the more recent reports (Spivak et al., 2000; Montoya et al., 2003; Shiloh et al., 2003) as well as my own clinical experience as a psychiatrist at the front for almost three decades, the incidence of definite NMS does not appear to exceed 2-3 cases out of one thousand consecutive patients treated with antipsychotics, as long as precautionary measures and monitoring are cautiously and sufficiently employed for the early recognition and prevention of NMS.

\subsection{Clinical features}

The principal clinical manifestations of NMS are characterized by the symptoms related to the following 4 major areas: (1) hyperpyrexia, (2) extrapyramidal symptoms (EPS), (3) altered mental status, and (4) autonomic instability. Hyperthermia is prerequisite to being diagnosed as NMS (Kurlan et al., 1984; Levenson, 1985; Addonizio et al., 1987; Caroff \& Mann., 1988; Rosebush \& Stewart, 1989), with a body temperature exceeding $38^{\circ} \mathrm{C}$ in most cases, and as high as $40-41{ }^{\circ} \mathrm{C}$ in some patients. The EPS are also noted in almost all cases reported as NMS, typically represented as muscle rigidity accompanied by tremors, which is often described as "lead-pipe" or "plastic". Other forms of EPS including focal dystonia, sialorrhea, dysphagia, dysarthria, opisthotonus, oculogyric crisis, chorea and dyskinesia are sometimes observed as accompanying symptoms. Altered mental status includes varied levels of consciousness disturbances ranging from drowsiness to coma, confusion, agitation, delirium, stupor, mutism and so on. Involvement of the autonomic system is manifested by severe tachycardia, labile blood pressure, profuse diaphoresis, dyspnea and incontinence. 
Although laboratory abnormalities of NMS are nonspecific, elevation of serum creatine phosphokinase (CPK) (>99\% derived from muscle fraction) is noted in almost all cases, which reflects significant muscle damage during development of NMS. In severely affected cases, it often exceeds 10,000 IU/liter with a high risk of development of myoglobinuria and renal failure. Leukocytosis is also seen in almost all patients with NMS. Hepatic enzymes are occasionally elevated but less dramatically than CPK.

Diagnosis of NMS is made based on the above-mentioned clinical symptoms and laboratory findings when these abnormalities develop subsequent to the initiation of or increase in antipsychotics and other medical conditions can be excluded. The typical cases with "fullblown" symptoms appear to be diagnosed with ease if the physician is aware of the concept of NMS. Several diagnostic criteria for NMS have been proposed by different researchers (Levenson, 1985; Addonizio et al., 1986; Pope et al., 1986; Adityanjee et al., 1988; J.H. Friedman et al., 1988; Keck et al., 1989a, 1989b; Caroff et al., 1991; Nierenberg et al., 1991; Caroff \& Mann, 1993; Adityanjee et al., 1999b), and here presented in Table 1 is the research criteria for NMS described in DSM-IV-TR (Frances et al., 2000).

\begin{tabular}{|ll|}
\hline A. & The development of severe muscle rigidity and elevated temperature associated \\
with the use of neuroleptic medication. \\
\hline B. \\
Two (or more) of the following: \\
$(1) \quad$ diaphoresis \\
$(2) \quad$ dysphagia \\
$(3) \quad$ tremor \\
$(4) \quad$ incontinence \\
$(5) \quad$ changes in level of consciousness ranging from confusion to coma \\
$(6) \quad$ mutism \\
$(7) \quad$ tachycardia \\
$(8) \quad$ elevated or labile blood pressure \\
$(9) \quad$ leucocytosis \\
(10) laboratory evidence of muscle injury (e.g., elevated CPK) \\
C. The symptoms in Criteria A and B are not due to another substance (e.g., \\
phencyclidine) or a neurological or other general medical condition (e.g., viral \\
encephalitis). \\
\hline D. The symptoms in Criteria A and B are not better accounted for by a mental disorder \\
(e.g., Mood Disorder With Catatonic Features).
\end{tabular}

Table 1. Research criteria for NMS described in DSM-IV (Frances et al., 2000)

\subsection{Precipitating agents}

Virtually all classes of dopamine $\mathrm{D}_{2}$ receptor antagonists have been associated with NMS. This includes not only neuroleptics in a narrow sense (either typical or atypical antipsychotics) prescribed for the control of psychotic symptoms, but also several classes of drugs with the potential to block $\mathrm{D}_{2}$ receptors in CNS used as antidepressants, antiemetics, anesthetics, and sedatives (e.g., Robinson et al, 1985; L.S. Friedman et al., 1987; Taylor \& Schwartz, 1988; Madakasira, 1989; Spirt et al., 1992; Chan-Tack, 1999). 
Aside from cases with NMS associated with the use of antagonists for dopamine $\mathrm{D}_{2}$ receptors, the clinical features identical or closely resemblant to NMS have been occasionally reported to develop during the course of the treatment with antiparkinsonian drugs, especially after the withdrawal or reduction of them, in patients with Parkinson's disease (Henderson \& Wooten, 1981; Toru et al., 1981; J.H. Friedman et al., 1985; Y. Yamawaki \& Ogawa, 1992; Serrano-Dueňas, 2003; Takubo et al., 2003). In these cases, it may be inappropriate to use the term NMS since the patients were not receiving "neuroleptics" (Addonizio et al., 1987), and some strict researchers refer to such cases as "NMS-like state" (Toru et al., 1981), "malignant dopaminergic syndrome" (Serrano-Dueňas, 2003), or simply as "malignant syndrome" (Takubo et al., 2003). Irrespective of how it is called, the underlying pathophysiology to precipitate the clinical course in these patients is supposed to be dopaminergic hypofunction in CNS, which is identical to that in the patients with NMS induced by the use of antipsychotics. Therefore, it appears acceptable to consider the episode fulfilling the clinical features of NMS in patients with Parkinson's disease as a variant of NMS, even if it is not induced by the use of neuroleptics.

The similar syndromes have also been reported to be caused by numerous other classes of drugs with different mechanisms of action [e.g., lithium, clomipramine, nortryptiline, SSRIs, benzodiazepines] (Kellam, 1987a; Ananth et al., 2004a, but see also Assion et al., 1998), and even in the absence of any pharmacotherapeutic intervention (the so-called lethal catatonia), and thus some researchers have commented that NMS is a misnomer (Singh \& Maguire, 1987; Brennan et al., 1988). They proposed novel names such as "iatrogenic malignant syndrome" (Singh \& Maguire, 1987) or "pyrexial catatonia" (Kellam, 1987b) instead of NMS. Heyland \& Sauvé (1991) suggested a new label "drug-induced central hyperthermic syndrome" for such cases. In my opinion, however, these designations are too vague as a diagnosis in clinical settings, and it should be avoided to broaden the concept of NMS to too much extent.

\subsection{Risk factors}

As shown in Table 2, there had been many potential risk factors for NMS identified or postulated in numerous reviews, case series, and reports published until 1989 (Keck et al., 1989a). Among them, demographic items such as sex, age, and psychiatric diagnosis are not of essential importance as risk factors (Caroff \& Mann, 1993). It should be kept in mind that NMS can develop regardless of sex, age, and psychiatric diagnosis, when antipsychotic agents are administered to a patient. Case-controlled studies (Keck et al., 1989a; Berardi et al., 1998; Viejo et al., 2003) have indicated psychopathological features such as agitation, confusion, disorganized behavior, and catatonia, as well as pharmacological features such as higher neuroleptic dose at greater rates of dose increase and parenteral neuroleptic injections, as risk factors. It has been reported that antecedent existence of EPS including akathisia is also a risk factor of NMS (Berardi et al., 1998). NMS occurs independent of climate and ambient conditions (Caroff \& Mann, 1993), and Viejo et al. (2003) were unable to find a significant difference in environmental temperature at onset of clinical symptoms of NMS between the cases and matched-controls. Considering various cases of NMS reported to develop during heat waves (Shalev et al., 1988; Fitzgerald et al., 1997), however, adverse climate conditions with high temperature and excessive humidity may be important in some cases to trigger the development of NMS. High serum CPK levels during psychotic episodes may also be a risk factor for NMS (Hermesh et al., 2002). 


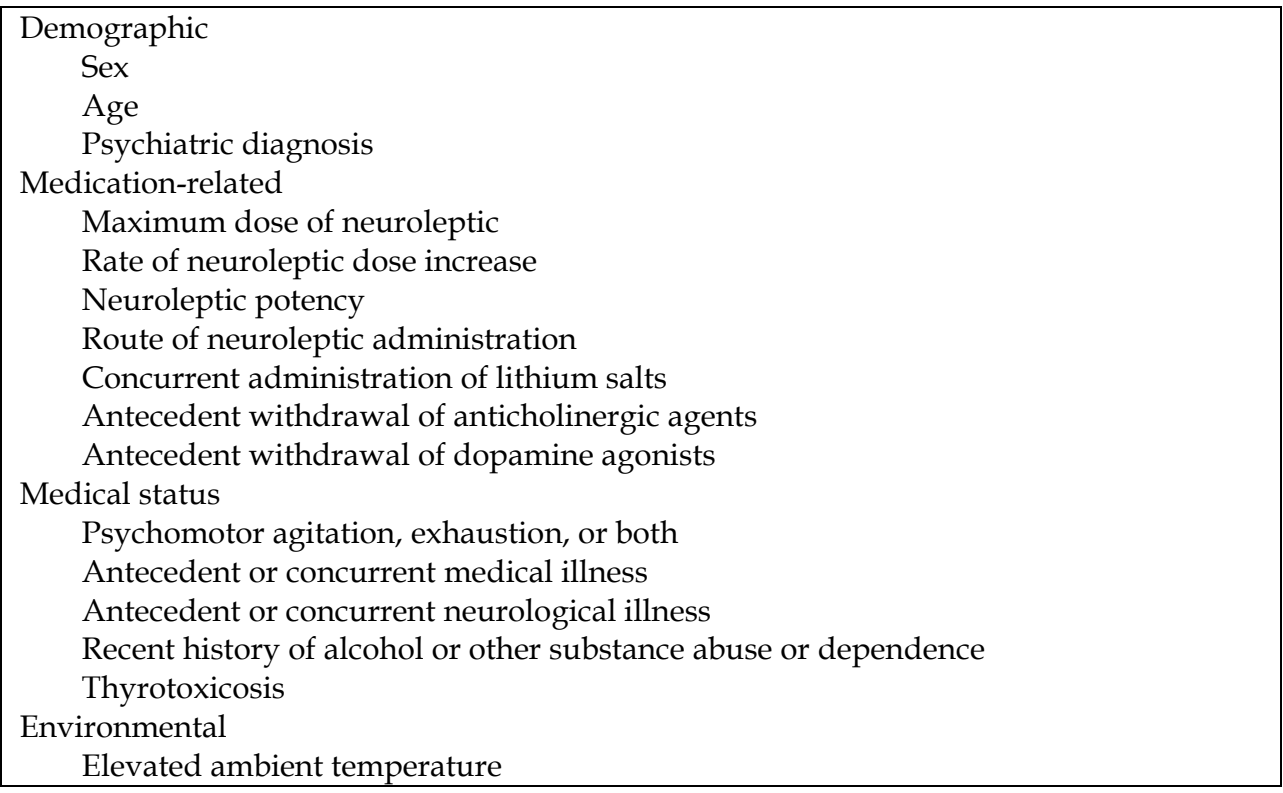

Table 2. Risk factors for NMS identified or postulated until the report by Keck et al. (1989a)

Familial occurrence of NMS has been reported occasionally (Deuschl et al., 1987; Otani et al., 1991; Ziegenbein et al., 2006), suggesting that a predisposition to NMS is genetically governed in some cases. Extreme caution should be then paid to a patient with a family history of NMS, to whom it is necessary to initiate pharmacotherapy with antipsychotics.

\subsection{Clinical course and outcome}

Although the reported duration of exposure to antipsychotics prior to the development of NMS is extremely varied, the majority of cases occur within 1 to 2 weeks after the initiation of an offending drug (Shalev \& Munitz, 1986; Addonizio et al., 1987; Caroff et al., 1988). Though nonspecific, the following signs and symptoms have been reported to precede NMS in some cases: unexpected changes in mental status, particularly obtundation or new-onset catatonia; episodic tachycardia, tachypnea, or hypertension; incontinence; low-grade temperature elevations; dysarthria, dysphagia, diaphoresis, sialorrhea, rigidity, myoclonus, tremor or other EPS unresponsive to antiparkinsonian agents; and unexplained elevation in serum CPK (Caroff et al., 1991; Caroff \& Mann, 1993). Since almost all of these are themselves constituent symptoms of NMS (see above), it may be possible to diagnose a patient with such prodromal or early symptoms as NMS, depending on the diagnostic criteria of NMS adopted. At any rate, it is practically very important to be aware of sequential progression of symptoms of NMS in order to facilitate prompt recognition and interventions to abort the symptoms in its incipient stage. Analysis of the temporal sequence of the four predominant clinical features of NMS has indicated that either altered mental status or muscle rigidity precedes hyperthermia and autonomic dysfunction in the majority of fulminant NMS cases, most typically with the following order: (1) changes in mental status; (2) muscle rigidity; (3) hyperthermia; and (4) autonomic dysfunction (Velamoor et al., 
1994). Woodbery \& Woodbery (1992) proposed five discrete stages toward the progression of NMS, from stage I or drug-induced parkinsonism to stage $\mathrm{V}$ (the severest form of fulminant NMS). This spectrum-based concept of NMS (Fig. 1) may be practically useful to comprehend the progression of symptoms, at least in typical cases (Odagaki, 2009).

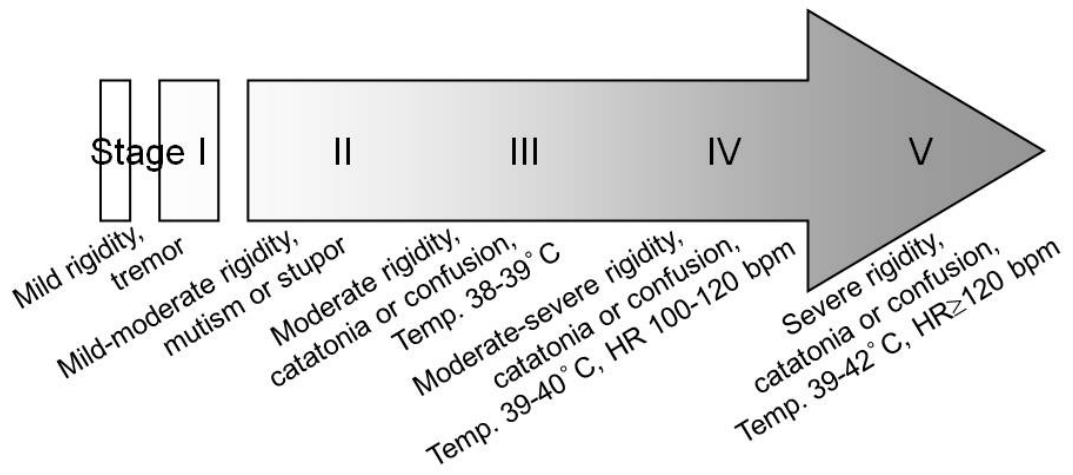

Fig. 1. The typical progression of symptoms of NMS from the mildest stage I (drug-induced parkinsonism) through stage V or the severest form of NMS (Odagaki, 2009). Stages I-V are originally proposed by Woodbury and Woodbury (1992) and adapted by Strawn et al.

(2007).

Once antipsychotics are stopped, NMS is self-limited barring complications, with the duration to resolution of NMS up to two weeks in the majority of cases (Shalev \& Munitz, 1986; Addonizio et al., 1987; Caroff et al., 1988). The notion that prompt withdrawal of the offending agent at early stage can prevent progression to definite NMS has been corroborated by the study reported by Shiloh et al. (2003).

The clinical course of NMS can be modified by concurrence of many complications. Although most medical problems are reported as complications (Addonizio et al., 1987), one of the most common and serious complications of NMS is acute renal failure caused by rhabdomyolysis (Levenson, 1985). As it has been reported that renal failure and myoglobinemia are associated with a significantly higher risk of mortality in NMS (Shalev et al., 1989), careful monitoring is necessary as to serum CPK levels, myoglobinemia / myoglobinuria, and renal functions throughout the course of NMS. As impressed with its designation, NMS is potentially lethal (Kellam, 1987a). The mortality rate was, however, reported even in the late 1980s to be apparently declined as compared with the former reports, and the overall rate of mortality for patients without concurrent organic diseases was reported as less than $10 \%$ since 1984 (Shalev et al., 1989). The survey on NMS cases conducted in Japan also showed a clear chronological decline of mortality rate, which reached below $10 \%$ in the latest years of the survey (S. Yamawaki et al., 1990).

Although persistent, long-term clinical sequelae of NMS were historically considered rare, there have been substantial case reports with deficits related to complications or severity of the syndrome, particularly hypoxia or hyperthermia. As neuropsychiatric sequelae of NMS, Adityanjee et al. (2005) raised CNS dysfunctions manifested as cognitive impairment or as 
parkinsonian syndrome, peripheral neurologic impairment such as peripheral neuropathy, and psychological impairment including severe depression.

\subsection{Differential diagnosis}

Differential diagnosis is of prime importance, because NMS constituted with nonspecific symptoms and laboratory abnormalities is a diagnosis of exclusion. The disorders listed in Table 3 (Strawn et al., 2007) should be considered as differential diagnoses.

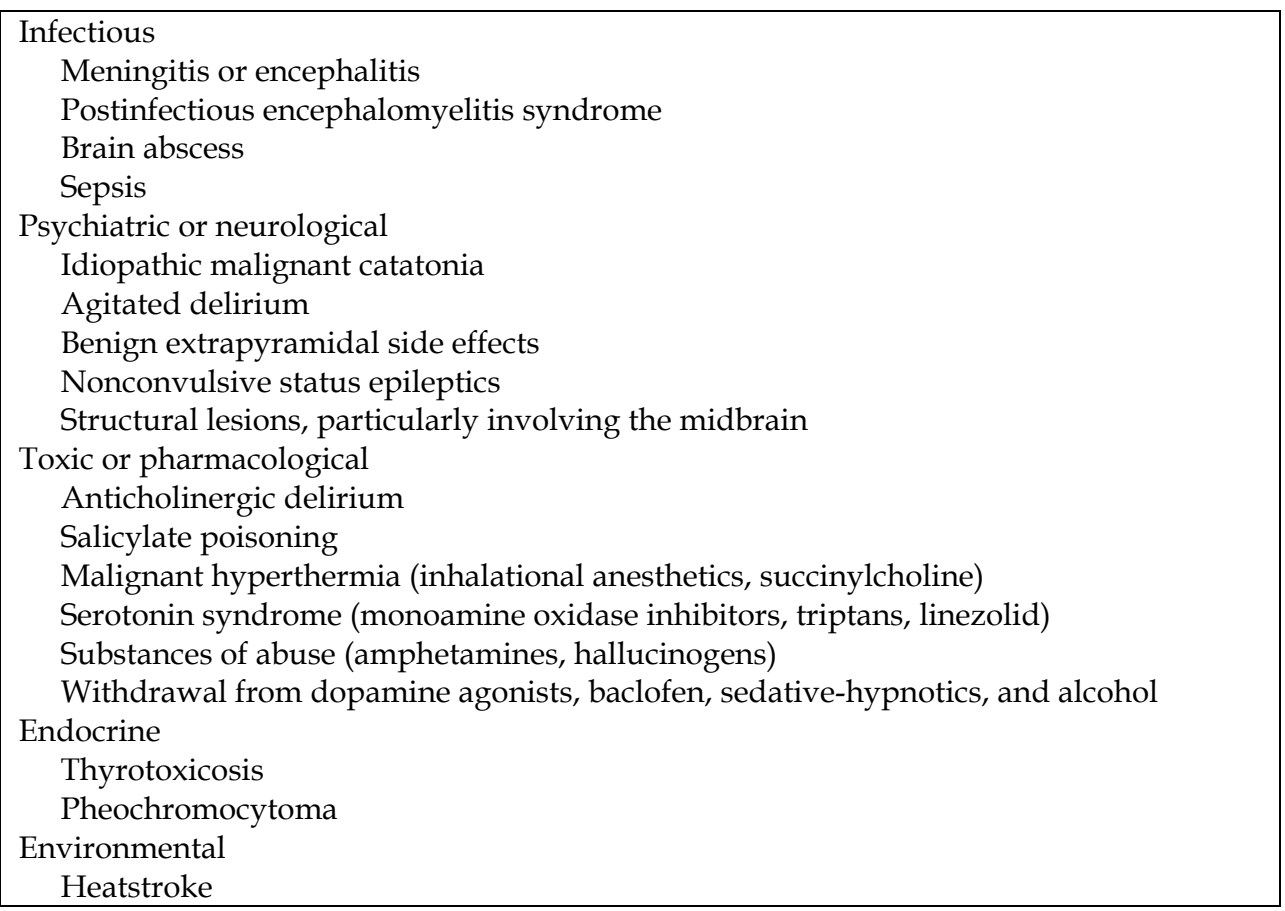

Table 3. Differential diagnosis of NMS (Strawn et al., 2007)

Among these, idiopathic malignant (lethal) catatonia and SS are of special importance from the practical as well as theoretical viewpoints. Idiopathic malignant catatonia, a lifethreatening febrile neuropsychiatric syndrome that had been described well several decades before the advent of antipsychotic drugs, is clinically quite similar to, and often indistinguishable from, NMS (Mann et al., 1986). Some researchers indeed regard NMS as a drug-induced iatrogenic form of malignant catatonia with the same underlying pathophysiology (Mann et al., 1986; White, 1992; Fink, 1996a; Carroll \& Taylor, 1997; Fricchione et al., 2000). On the other hand, Castillo et al. (1989) emphasized the importance of differentiating these two syndromes clinically. In response to the editorial by Fink (1996a), Northhoff (1996) also contributed a correspondence against the notion that NMS and catatonia were variants of the same disorder. The similar debate has been held on the discrimination between NMS and SS (Fink, 1996b; Kontaxakis et al., 2003; Odagaki, 2009; Steele et al., 2011). It is beyond the scope of this article to have a detailed discussion on the 
possibility that NMS belongs to a spectrum of the same disorder that contains catatonia and/or SS. Nevertheless, clinicians should keep an effort to differentiate NMS from other pathological conditions as long as there may be some differences in etiology, pathophysiology, and treatment.

\subsection{NMS associated with atypical antipsychotics}

With widespread use of atypical antipsychotics in recent years, NMS induced by these drugs has attracted much attention of clinicians and researchers (Caroff et al., 2000; Farver, 2003; Ananth et al., 2004b; Trollor et al., 2009). At the same time, great interest has also been taken in the concept of "atypical NMS", which is often presumed to be more associated with atypical antipsychotics than with conventional drugs (Picard et al., 2008). Though still controversial, the review of Trollor et al. (2009) suggests that NMS associated with atypical antipsychotics manifests in a typical manner, with one notable exception of clozapineinduced NMS which appears to be less associated with EPS. It should be borne in mind that even the atypical antipsychotics have the potential to precipitate the patient to NMS, as long as they are dopamine $\mathrm{D}_{2}$ receptor antagonists.

\subsection{Pathophysiology}

Although the precise pathophysiological mechanisms underlying NMS are still unknown, antipsychotic-induced dopamine $\mathrm{D}_{2}$ receptor blockade in the striatum and hypothalamus likely plays a pivotal role, at least at its initial stages, for the development of NMS (Mann et al., 2000). In addition to dopaminergic dysfunction, complex alterations in functioning of different neurotransmitters in various brain regions, e.g., norepinephrine, serotonin, $\gamma$ aminobutyric acid (GABA), and glutamate, are believed to be involved in the expression of multifarious clinical features of NMS (Ananth, 2004a). Through complex neurochemical as well as structural interactions among multiple neural transmission systems, a vicious circle likely develops to end a failure of homeostasis, irreversibly and lethal in some cases, that is involved in maintenance of consciousness and regulation of extrapyramidal motor function, body temperature, and autonomic functions. Especially in the fulminant cases with severe autonomic instability, uncoordinated hyperactivity of the peripheral sympathoadrenal systems, culminating in an end-stage hypermetabolic syndrome, is hypothesized (Feibel \& Schiffer, 1981; Gurrera \& Romero, 1992; Gurrera, 1999).

\subsection{Treatment}

One of the most important, and probably the most effective measures to avoid "malignant" sequence of the syndrome is a removal of the potentially offending drug(s) as prompt as possible. Although the treatment of NMS should be individualized for each patient depending on the clinical features and situations, the mainstay is good supportive medical care against extreme hyperthermia, dehydration, metabolic acidosis, nutritive and electrolyte imbalance, and occurrence of the complications including cardiorespiratory and/or renal failures, aspiration pneumonia, rhabdomyolysis, and coagulapathies. Several specific treatments recommended for management of NMS (Table 4) should be taken into consideration as additional therapeutic options, based on the severity and clinical course (Sakkas et al., 1991a, 1991b; Davis et al., 2000). However, it should be stressed that these 
specific remedies for NMS are derived from empirical reports or theoretical grounds, rather than based on prospective, randomized controlled studies (Susman, 2001). For instance, conflicting results have been shown even about the usefulness of dantrolene and bromocriptine, the two most well established drugs for treatment of NMS (Rosenberg \& Green, 1989; Rosebush et al., 1991; Reulbach et al., 2007).

\begin{tabular}{|c|c|}
\hline Treatment with & Comments \\
\hline Anticholinergics & $\begin{array}{l}\text { Still controversial, but may be useful in mild or early cases } \\
\text { to help attenuate EPS (Woodbury and Woodbury, 1992) }\end{array}$ \\
\hline Benzodiazepines & $\begin{array}{l}\text { May be useful when catatonic symptoms predominate } \\
\text { (Francis et al., 2000) }\end{array}$ \\
\hline \multicolumn{2}{|c|}{ Dopaminergic agonists } \\
\hline Bromocriptine & $\begin{array}{l}\text { One of the most well established pharmacologic agents for } \\
\text { NMS (Rosenberg \& Green, 1989; Sakkas et al., 1991a, 1991b) }\end{array}$ \\
\hline Levodopa & $\begin{array}{l}\text { Successful cases reported (Harris et al., 1987; Sakkas et al., } \\
\text { 1991a; Nisijima et al., 1997) }\end{array}$ \\
\hline Amantadine & $\begin{array}{l}\text { Its use associated with a statistically significant decrease in } \\
\text { mortality (Sakkas et al., 1991a, 1991b) }\end{array}$ \\
\hline Dantrolene & $\begin{array}{l}\text { One of the most well established pharmacologic agents for } \\
\text { NMS (Rosenberg \& Green, 1989; Sakkas et al., 1991a, 1991b) }\end{array}$ \\
\hline $\begin{array}{l}\text { Electroconvulsive } \\
\text { therapy (ECT) }\end{array}$ & $\begin{array}{l}\text { Should be considered when pharmacotherapy has failed or } \\
\text { when idiopathic malignant catatonia cannot be ruled out } \\
\text { (Davis et al., 1991; Trollor \& Sachdev, 1999) }\end{array}$ \\
\hline
\end{tabular}

Table 4. Specific therapeutic remedies proposed for treatment of NMS

\section{Serotonin toxicity (serotonin syndrome)}

\subsection{Historical background}

The term "serotonin syndrome (SS)" was originally derived from the experimental behavioral model in rodents (Jacobs, 1976; Gerson \& Baldessarini, 1980), and introduced into clinical medicine in 1982 for the first time to describe the toxic reactions to the coadministration of a monoamine oxidase inhibitor (MAOI) clorgyline and a tricyclic antidepressant (TCA) clomipramine in two obsessive-compulsive disorder patients (Insel et al., 1982). In fact, however, many similar case reports date back to 1950s (e.g., Mitchell, 1955), the era of prevailing use of MAOIs such as isoniazid and iproniazid as antidepressants or antituberculous drugs (Gillman, 1998). The first review article on SS, based on the summary of 12 clinical reports between 1982 and 1990 (Sternbach, 1991), was instrumental in popularizing the syndrome to physicians, and awareness of SS as a distinct clinical entity increased the number of reported cases diagnosed as SS in the following two decades.

As pointed out by Isbister \& Buckley (2005), the term SS is often equivocally used and the clinical literature on this subject is sometimes inconsistent and confused. In the present article, the term "serotonin toxicity (ST)" is generally used to refer to the clinical state with any signs or symptoms reasonably attributable to excess serotonin caused by serotonergic agents. 


\subsection{Clinical features and diagnosis}

According to the conventional definition based on relatively severe cases reported in the literature (Sternbach, 1991), SS can be described as a clinical triad of (1) mental-status changes, (2) autonomic hyperactivity, and (3) neuromuscular abnormalities. The diagnostic criteria for SS suggested by Sternbach (1991) are shown in Table 5.

A. Coincident with the addition of or increase in a known serotonergic agent to an established medication regimen, at least three of the following clinical features are present:

1) mental status changes (confusion, hypomania)

2) agitation

3) myoclonus

4) hyperreflexia

5) diaphoresis

6) shivering

7) tremor

8) diarrhea

9) incoordination

10) fever

B. Other etiologies (e.g., infectious, metabolic, substance abuse or withdrawal) have been ruled out.

C. A neuroleptic had not been started or increased in dosage prior to the onset of the signs and symptoms listed above.

Table 5. Suggested diagnostic criteria for SS (Sternbach, 1991)

In practice, the signs and symptoms of ST range from tremor and diarrhea in mild cases to delirium, neuromuscular rigidity, and excessive hyperthermia in life-threatening cases, depending on the extent of serotonin excess. The clinical sequelae of serotonin excess are best thought of as a spectrum of toxicity, rather than a defined clinical entity (syndrome) with clear prognostic importance (Dunkley et al., 2003). Randomski et al. (2000) divided the cases into: (1) mild state of serotonin-related symptoms; (2) serotonin syndrome (full-blown form); and (3) toxic states (Fig. 2).

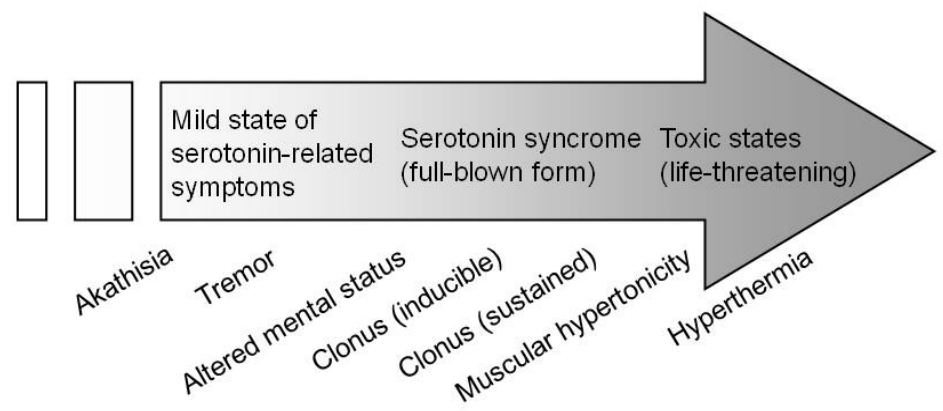

Fig. 2. Spectrum concept of ST (Adapted from Boyer \& Shannon, 2005), with three clinical stages designated by Radomski et al. (2000). 
To assess the severity of ST, the scale developed by Hegerl et al. (1998) may be useful. When adapted to the depressed patients treated with paroxetine, it was positively correlated with paroxetine concentrations and inversely correlated with auditory evoked potential (an indirect measure of serotonergic activity). Their scale consists of the following nine items each rated from 0 to 3: agitation, disorders of orientation, myoclonus, hyperreflexia, tremor, dizziness, hyperthermia, sweating, and diarrhoea.

Dunkley et al. (2003) analyzed the clinical data in 2222 consecutive cases of self-poisoning with serotonergic drugs, and found that several clinical features were associated with the diagnosis of SS. They developed the diagnostic decision rules for ST (Fig. 3), based on the results of their analysis as well as by including muscular hypertonicity and hyperthermia, both characteristic symptoms of the severe, life-threatening SS cases.

The onset of symptoms is usually rapid, with clinical findings often occurring within minutes, and in most cases within 24 hours, after initial use, an overdose, or a change in dosing of the offending drug(s) (Mason et al., 2000). It should be noted that the syndrome is often misdiagnosed initially, especially as exacerbation of psychiatric disorder with anxiety or agitation (MacKay et al., 1999; Attar-Herzerg et al., 2009). Patients with mild manifestations may present with subacute or chronic symptoms, whereas severe cases may progress rapidly to death (Sporer, 1995; Boyer \& Shannon, 2005). The most notorious example of such fatal patients is the 'Libby Zion' case (Asch \& Parker, 1988). Other severe complications of SS include seizures, disseminated intravascular coagulation, respiratory failure, severe hyperthermia, ventricular arrhythmia, and rhabdomyolysis (Sporer, 1995). Milder cases show resolution of the symptoms typically within 24 hours once the offending agents are discontinued (Sternbach, 1991).

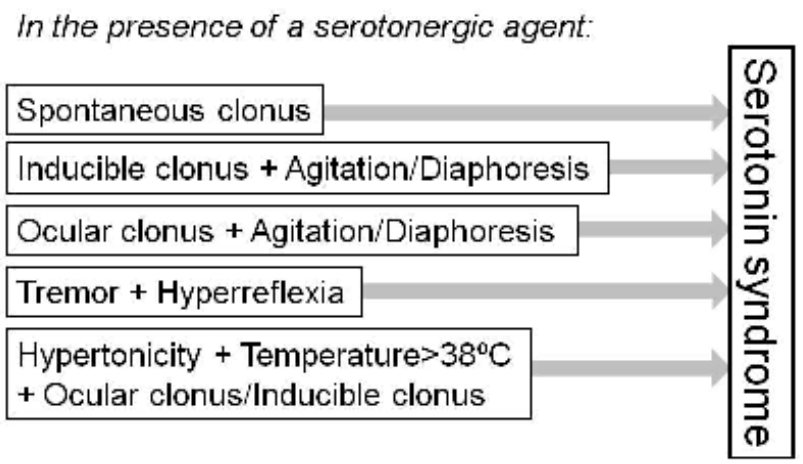

Fig. 3. Diagnostic criteria for SS proposed by Dunkley et al. (2003).

There are no confirmatory or specific laboratory tests available for the diagnosis of SS. Laboratory tests are best used to identify potential complications and assist in overall patient care. Elevated CPK has been reported in 18 \% (Mills, 1997) or 34 \% (Keck \& Arnold, 2000) of the cases, usually associated with muscle rigidity and rhabdomyolysis. Electroencephalograms (EEG) may show general slowing, consistent with diffuse encephalopathy (Mills, 1997). Highly abnormal EEG findings, such as (poly-)spikes and waves (Lejoyeux et al., 1992) and pronounced triphasic waves (Dike, 1997), were also reported in patients with SS. 


\subsection{Precipitating agents}

Virtually all medications that potentiate serononergic neurotransmission in the CNS have been reported in association with the cases of SS (Keck \& Arnold, 2000), either alone or in combination. As shown in Table 6, the most common drug combinations causing the SS are MAOIs and antidepressants (SSRIs or TCAs) (Sporer, 1995). The severity of ST precipitated by the offending drug(s) is predictable well according to the serotonin levels measured in animal experiments (Gillman, 2006). The highest serotonin levels determined by microdialysis studies is achieved by the combination of MAOI and serotonin reuptake inhibitor (SRI) (100-fold as compared with baseline), followed by MAOI plus L-tryptophan (15-fold), MAOI alone (10-fold), moclobemide plus 3,4-methylenedioxymethamphetamine (MDMA) (10-fold), MDMA alone (5-fold), SSRI alone (3-fold), venlafaxine alone (3-fold), moclobemide alone (1.5-fold), TCA alone (1.25-fold), and mirtazapine alone (1.2-fold). Although mirtazapine alone stands at the lowest risk for ST, there has been a case report of severe SS induced by mirtazapine monotherapy (Hernández et al., 2002).

\begin{tabular}{|ll|}
\hline Drug combination & Number of cases \\
\hline MAOI + Pethidine (Meperidine) & 9 \\
MAOI + Dextromethorphan & 4 \\
MAOI + Tryptophan & 9 \\
Reversible MAOI + TCA & 2 \\
Reversible MAOI + SSRI & 5 \\
MAOI-B + SSRI & 6 \\
MAOI-B + TCA & 2 \\
MAOI + SSRI & 24 \\
MAOI + TCA & 16 \\
SSRI + Dextromethorphan & 1 \\
SSRI + Tryptophan & 5 \\
SSRI + Lithium & 1 \\
SSRI + Pentazocine & 1 \\
Buspirone + Trazodone & 1 \\
TCA + Lithium & 1 \\
Bromocriptine + Levodopa & 1 \\
Phenelzine + Trazodone + Dextropropoxyphene & 1 \\
Clomipramine & 1 \\
MDMA & 2 \\
Fentanyl + Sertraline & 1 \\
Sertraline & 1 \\
Ademetionine (S-Adenosyl methionine) + Clomipramine & 1 \\
\hline
\end{tabular}

Table 6. List of the agents reported to cause SS (Sporer, 1995)

\subsection{Differential diagnosis}

The differential diagnosis of SS involves disorders producing cognitive and behavioral, neuromuscular, and autonomic nervous system dysfunction with or without hyperthermia (Keck \& Arnold, 2000), such as anticholinergic poisoning, malignant hyperthermia, and NMS (Boyer \& Shannon, 2005). SS can be confused with NMS, particularly when both 
serotonergic and neuroleptic drugs had been used concomitantly in a patient showing severe life-threatening symptoms and/or complications described before. The following features are raised by Gillman (1999) for differentiation between the two syndromes: NMS, slow onset (days to weeks) and slow progression over 24-72 hours in association with neuroleptics versus SS, both rapid onset and rapid progression (minutes to hours) in association with a combination of serotonergic drugs; NMS, bradykinesia and lead pipe rigidity versus SS, hyperkinesias and clonus; and NMS, an idiosyncratic reaction to therapeutic dosages versus SS, a manifestation of toxicity (usually to a combination of drugs) to which everyone is liable. The differential diagnosis between SS and NMS can be further complicated when atypical antipsychotics are included in the prescription, because some of atypical antipsychotics are $5-\mathrm{HT}_{1 \mathrm{~A}}$ receptor agonist by themselves (Odagaki, 2009).

\subsection{Pathophysiology}

It has been well accepted that excess serotonergic signal transduction in CNS, resulting mostly from increase in serotonin concentrations by several mechanisms, explains most, if not all, of the clinical features of ST or SS. However, it should be noticed that much of our understanding of the pathophysiology of SS derives from preclinical data. As indicated by Isbister \& Buckley (2005), there is no evidence that serotonin behavioral syndrome defined in experimental behavioral pharmacology and ST/SS described in clinical medicine are even similar in terms of phenomenology or underlying mechanisms. The significant confusion in the literature has been created especially as to the pathophysiological roles of 5-HT $\mathrm{HA}_{1 \mathrm{~A}}$ and 5$\mathrm{HT}_{2 \mathrm{~A}}$ receptors implicated in SS. As discussed earlier (Isbister \& Buckley, 2005; Odagaki, 2009), the possible important roles of $5-\mathrm{HT}_{2 \mathrm{~A}}$ receptors in pathogenesis of SS, in particular the severe cases with hyperthermia and/or muscle hypertonicity, should be taken into consideration.

\subsection{Treatment}

Of most importance are prompt recognition of toxicity and discontinuation of offending medications in management of ST. Most cases of ST, even if represented as a full-blown form of SS, are self-limiting, if medications are withdrawn promptly at their early stages and no complications occur. In some patients, however, life-threatening severe toxicity can develop. Severe toxicity is more likely in patients ingesting overdosed serotonergic agent(s) or at least two drugs with different mechanisms of action, with combinations of SSRIs and a MAOI being the most common (Isbister \& Buckley, 2005). The Toxic Exposure Surveillance System in the United States reported over 100 deaths related to ingestion of SSRIs in 2004 (Watson et al., 2005), though it was unclear whether all of these cases could be diagnosed clinically as SS.

Most cases with ST can be managed by means of supportive care with intravenous fluids as well as with symptomatic therapies according to the clinical features and severity, e.g., aggressive external cooling for hyperthermia, benzodiazepines or barbiturates for seizures, and benzodiazepines for muscle rigidity, myoclonus, or agitation. The use of nondepolarizing paralyzing agents under mechanical ventilation is indicated when muscle rigidity remains refractory to benzodiazepines (Mills, 1995; Isbister \& Buckley, 2005). 
In the severe SS cases, more specific therapy may be considered. The most commonly used drugs have been methysergide, cyproheptadine, and chlorpromazine (Mills, 1995; Gillman, 1999). However, the SS cases reported to be successfully treated with these medications are all anecdotal, with randomized controlled trials lacking. Based on the pharmacological properties of these drugs as well as on the experimental results using an animal model of SS (Nisijima et al., 2007), Isbister \& Buckley (2005) suggested that nonselective 5-HT2 antagonists such as ketanserin or selective $5-\mathrm{HT}_{2 \mathrm{~A}}$ antagonists such as atypical antipsychotics may be effective for the treatment of SS. The use of atypical antipsychotics for treating SS is, however, not recommended, at least when NMS is not clearly excluded. There has been a report of the patient who showed SS caused by sertraline intake and consecutively NMS induced by risperidone (J.-M. Kim et al., 2007).

\section{SSRI discontinuation syndrome}

\subsection{Background}

Pharmacotherapy for mood and anxiety disorders has been dramatically changed during the last two decades, especially with an expanding increase in use of SSRIs for the treatment of broad spectrum including depression, varied types of anxiety, eating, obsessivecompulsive, and impulse-control disorders. In parallel with the wide-spread use of SSRIs, reports of SSRI discontinuation syndrome have been increased. As described below, it sometimes involves alterations in mental function, which may be interpreted as a relapse or worsening of the original disorders. This is the reason why the author intends to summarize the syndrome in brief here in this chapter.

Antidepressant discontinuation syndrome (Dilsaver \& Greden, 1984; Dilsaver et al., 1987; Lejoyeux et al., 1996) had been well identified since first reported for imipramine in 1959 (Andersen \& Kristiansen, 1959; Mann \& MacPherson, 1959, as cited in these three reviews). The initial SSRI discontinuation syndrome was described for fluoxetine in 1988 (Cooper, 1988), and subsequent many case reports and review articles indicated it can develop for all SSRIs. Some researchers include discontinuation symptoms related with other antidepressants than SSRIs, such as venlafaxine, nefazodone, trazodone, and mirtazapine, in the same syndrome (Schatzberg et al., 1997a; Tamam \& Ozpoyraz, 2002).

Although the terms discontinuation and withdrawal are sometimes used interchangeably, the latter should be avoided for the patients treated with antidepressants including SSRIs, since these drugs are, unlike opiates or sedative-hypnotics, non-addictive (Schatzberg et al., 1997b; Shelton, 2006).

\subsection{Clinical features and diagnosis}

Schatzberg et al. (1997b) raised the hallmark features of SRI discontinuation syndrome, as shown in Table 7. The clinical symptoms of SSRI discontinuation syndrome resemble those of TCA discontinuation syndrome, which had been classified into the following five main categories (Dilsaver \& Greden, 1984; Dilsaver et al., 1987; Lejoyeux et al., 1996; Haddad, 1997; Taman \& Ozpoyraz, 2002): (1) gastrointestinal and general somatic distress symptoms, e.g., anxiety, agitation, muscle tension, nervousness, flu-like symptoms (fatigue, headache, sweating, myalgia), lethargy, nausea, vomiting, asthenia; (2) sleep disturbances, such as insomnia and excessive and vivid dreams, (3) movement disorders, e.g., akathisia, 
parkinsonism, unsteady gait, abnormal movements of mouth and tongue; (4) behavioral activation, such as panic attacks, delirium, mania or hypomania; and (5) miscellaneous symptoms, such as cardiac arrhythmias. In the case of SSRI discontinuation syndrome, however, cardiac arrhythmias are seldom or never observed (Haddad, 1998), probably due to their minimal or negligible antimuscarinic activity and cardiotoxicity. In addition to, and probably overlapped with, these symptoms commonly seen in TCA discontinuation syndrome, further three symptom clusters are described to follow SSRI termination, i.e., (1) problems with balance (dizziness, ataxia, vertigo); (2) sensory abnormalities (electric shocklike sensations, paresthesia); and (3) aggressive and impulsive behavior (suicide attempts, hoarding during discontinuation) (Haddad, 1998). The proposed diagnostic criteria (Black et al., 2000) are shown in Table 8.

\begin{tabular}{|c|c|}
\hline \multicolumn{2}{|r|}{ Hall mark features of SRI discontinuation syndrome } \\
\hline 1. & Not attributable to other causes \\
\hline 2. & $\begin{array}{l}\text { Emergent upon abrupt discontinuation, intermittent noncompliance (e.g., missed } \\
\text { doses, drug holidavs) and less frequently, with dose reduction }\end{array}$ \\
\hline 3. & Generally mild and short-lived \\
\hline 4. & Self-limiting but can be distressing \\
\hline 5. & $\begin{array}{l}\text { Rapidly reversed by the reintroduction of the original medication or the } \\
\text { substitution of one that is pharmacologically similar }\end{array}$ \\
\hline 6. & Minimized by slow tapering or by using a drug with an extended half-life \\
\hline
\end{tabular}

Table 7. Hall mark features of SRI discontinuation syndrome (Schatzberg et al., 1997b)

\begin{tabular}{|c|c|}
\hline Criterion & Description \\
\hline $\mathrm{A}$ & $\begin{array}{l}\text { Discontinuation of or reduction in dose of an SSRI after a period of use of at } \\
\text { least } 1 \text { month }\end{array}$ \\
\hline B & $\begin{array}{l}\text { Two (or more) of the following, developing within } 1 \text { to } 7 \text { days of criterion A } \\
\text { Dizziness, light-headedness, vertigo or feeling faint } \\
\text { Shock-like sensations or paresthesia } \\
\text { Anxiety } \\
\text { Diarrhea } \\
\text { Fatigue } \\
\text { Gait instability } \\
\text { Headache } \\
\text { Insomnia } \\
\text { Irritability } \\
\text { Nausea and/or emesis } \\
\text { Tremor } \\
\text { Visual disturbances }\end{array}$ \\
\hline C & $\begin{array}{l}\text { The symptoms in Criterion B cause clinically significant distress or } \\
\text { impairment in social, occupational or important areas of functioning }\end{array}$ \\
\hline $\mathrm{D}$ & $\begin{array}{l}\text { The symptoms are not due to a general medical condition and are not better } \\
\text { accounted for by recurrence of symptoms of the mental disorder for which } \\
\text { the SSRI was originally prescribed, or by concurrent discontinuation (or } \\
\text { reduction in use) of another psychoactive substance }\end{array}$ \\
\hline
\end{tabular}

Table 8 . The proposed diagnostic criteria for SSRI discontinuation syndrome (Black et al., 2000) 
SSRI discontinuation symptoms occur within 1 to 3 days subsequent to cessation of treatment or reduction in dose in the majority of cases (Black et al., 2000). In the case of fluoxetine, however, the symptoms can develop slower (Einbinder, 1995) due to its longer half-life compared with those of other SSRIs (Table 9). In most cases, the syndrome is mild and short-lived, with persisting duration usually not exceeding 1-3 weeks even if untreated (Coupland et al., 1996; Black et al., 2000).

\begin{tabular}{|lccc|}
\hline SSRI & \multicolumn{2}{c}{ Half-life (Haddad, 1998) } & Half-life \\
\cline { 2 - 3 } & Single dose & Multiple dose & (Schatzberg et al., 1997a) \\
\hline Paroxetine & $10 \mathrm{~h}$ & $21 \mathrm{~h}$ & $21 \mathrm{~h}$ \\
Fluvoxamine & $15 \mathrm{~h}$ & $22 \mathrm{~h}$ & $15 \mathrm{~h}$ \\
Sertraline & $26 \mathrm{~h}$ & $26 \mathrm{~h}$ & $26 \mathrm{~h}(66 \mathrm{~h})^{*}$ \\
Citalopram & $33 \mathrm{~h}$ & $33 \mathrm{~h}$ & \\
Fluoxetine & $1.9 \mathrm{~d}$ & $5.7 \mathrm{~d}(7-15 \mathrm{~d})^{*}$ & $84 \mathrm{~h}(4-16 \mathrm{~d})^{*}$ \\
\hline
\end{tabular}

"Half-life for an active metabolite shown in parentheses. $\mathrm{h}=$ hours, $\mathrm{d}=$ days.

Table 9. Half-lives of SSRIs (Schatzberg et al., 1997a; Haddad, 1998)

The half-life of the SSRI and its active metabolite (Table 9) probably contributes also to the likelihood of developing discontinuation syndrome for each drug. As anticipated from the half-life, the discontinuation events are more frequently and profoundly experienced with SSRIs with shorter half-life, in particular with paroxetine, and least often with fluoxetine that has the longest half-life (Coupland et al., 1996; Price et al., 1996; Rosenbaum et al., 1998).

\subsection{Pathophysiology}

As indicated above, plasma half-life of the SSRI is apparently one of the most important factors for occurrence of discontinuation syndrome, and thus the pathogenic mechanisms underlying SSRI discontinuation syndrome have to be supposed in accordance with this fact. The simplest and most plausible explanation is an abrupt decrease in availability of synaptic serotonin caused by withdrawal or decrease of the SSRI, in the face of downregulated serotonin receptors as a result of synaptic adaptation to long-term SSRI treatment (Schatzberg et al., 1997a).

In addition to this hypothesis, Schatzberg et al. (1997a) also raised the following three other mechanisms that possibly contribute to some clinical features of the syndrome: (1) secondary effects on other neurotransmitters than serotonin; (2) individual genetic or psychological differences; and (3) cholinergic rebound.

\subsection{Clinical implications and treatment}

Rosenbaum \& Zajecka (1997) indicated practical strategies for management of SRI discontinuation syndrome as follows: (1) reassuring patients that the symptoms are likely to be short-lived and mild; (2) for severe and distressing symptoms, the dosage of the drug prescribed immediately before the onset of discontinuation symptoms should be reinstituted and the rate of taper should be slowed; (3) all SRIs, with the exception of fluoxetine, should be gradually tapered; and (4) using or switching to agents with an extended half-life, such as fluoxetine, can help reduce the incidence of SRI discontinuation syndrome. 
The rate of tapering of the drug should depend on its pharmacokinetic and pharmacological profile, current dose, duration of treatment, other drugs concomitantly prescribed, the patient's physical, psychological, and social situations, and so on. Physicians who prescribe SSRIs should be aware of the risk of this syndrome at the termination of treatment, or even during maintenance therapy with a fixed dose. Missing even as few as two doses of a SSRI with a short half-life, which is very often unreported to the physician, might lead to the discontinuation symptoms (Kaplan, 1997). It should be noted some discontinuation symptoms, e.g., anxiety, irritability, fatigue, and insomnia, are sometimes hardly distinguishable from those of a relapse or recurrence of the primary affective or anxiety disorders.

\section{Other encephalopathic symptoms associated with psychotropic drugs}

\subsection{Hyponatremic encephalopathy}

Hyponatremia is among the most common electrolyte abnormalities encountered in clinical practice (Upadhyay et al., 2006, 2009), and it is not rare to experience encephalopathic symptoms such as seizures and altered consciousness due to severe hyponatremia, usually in association with psychogenic polydipsia (Dundas et al., 2007) or self-induced water intoxication (Vieweg et al., 1987; Riggs et al., 1991), in psychiatric patients treated with psychotropic drugs (de Leon et al., 1994).

Clinical severity of hyponatremia is related not only to the absolute level of serum sodium concentration, but also to the rate at which hyponatremia develops. Premonitory or early symptoms include nausea, vomiting, anorexia, disorientation, headache, fatigue, weakness, irritability, lethargy, confusion, and muscle cramps. Acute severe hyponatremia causes cerebral edema that can lead to coma, irreversible neurologic damage, and supratentorial cerebral herniation resulting in respiratory arrest from brain stem compression and death. In contrast, patients with chronic hyponatremia are often asymptomatic, even with serum sodium level as low as $120 \mathrm{mEq} / \mathrm{L}$ (Adroqué, 2005). As hyponatremia progresses, abovementioned premonitory, nonspecific symptoms are followed by neuropsychiatric symptoms such as seizures, hemiplegia, dysarthria, hallucinations, tremor, and coma. Patients may demonstrate an impaired response to verbal and painful stimuli, and exhibit bizarre behavior or experience auditory or visual hallucinations (Fraser \& Arieff, 1997). These psychiatric symptoms may mimic the manifestations of primary psychiatric disorders such as schizophrenia, and thus clinicians should be careful not to be misled into a judgment that the primary disorder is exacerbated. It also should be considered that compulsive water consumption in the late afternoon and evening may impair mental status and further exacerbate psychiatric symptoms (Siegel, 2008).

Although hyponatremia is derived from a variety of etiologies and classified into several types according to plasma and urine osmolarity as well as the volume of the total body water (Reddy \& Mooradian, 2009), hyponatremic encephalopathy in psychiatric patients is usually the so-called polydipsia-hyponatremia syndrome (psychogenic polydipsia) with hypotonic plasma osmolarity and euvolemic status of the total body water. However, compulsive water drinking alone is usually not sufficient to induce marked hyponatremia, because the normal kidney should theoretically be able to excrete water in excess of 20 liters per day and most patients actually ingest less water than that theoretically required (Vieweg 
et al., 1987; Fraser \& Arieff, 1997). As demonstrated by Goldman et al. (1988), the patients with polydipsia and hyponatremia are accompanied with impaired maximal urinary dilution and free-water clearance in response to water loading, suggesting renal abnormally enhanced sensitivity to low concentrations of arginine vasopressin (AVP). They also showed that the patients with a history of polydipsia and hyponatremia demonstrated a higher serum AVP levels as well as greater thirst independent of their serum osmolarity after receiving an infusion of hypertonic saline, suggestive of a downward shift in the threshold for AVP release and defect of osmoregulation of thirst, respectively (Siegel, 2008).

Most psychiatric patients with polydipsia-hyponatremia syndrome are thus associated with maladapted water and electrolyte homeostasis sustained principally by the action of neurohypophyseal antidiuretic hormone AVP. It has been demonstrated that lots of psychotropic drugs including antipsychotics, antidepressants, and anticonvulsants, can cause syndrome of inappropriate antidiuretic hormone secretion (SIADH) (Spigset \& Hedenmalm, 1995; Bhuvaneswar et al., 2009; Reddy \& Mooradian, 2009), and that antipsychotic-induced hyponatremia is most likely a result of SIADH (Meulendijks, 2010). Vieweg et al. (1987) also postulated that the syndrome of self-induced water intoxication and psychosis (SIWIP) was a subcategory of SIADH, with hypoosmolality and hyponatremia induced synergistically by polydipsia and released AVP, both of which were stimulated by psychosis. In the schizophrenic patients with polydipsia-hyponatremia syndrome, plasma AVP levels were shown to rise sharply after the pharmacological induction of psychotic symptoms with methylphenidate (Goldman et al., 1997). This mechanism may underlie the episodic escalation of polydipsia observed in psychotically exacerbated patients [psychosis, intermittent hyponatremia, and polydipsia (PIP) syndrome (Leadbetter et al., 1994)], which sometimes result in severe, life-threatening hyponatremic encephalopathy (Vieweg et al., 1985).

Treatment of hyponatremic symptoms in psychiatric patients depends on their severity as well as the rate of development (Siegel, 2008). Acute severe hyponatremic encephalopathy could be life-threatening, which thus has to be treated as an emergency with hypertonic saline to prevent cerebral edema. On the other hand, chronic hyponatremia associated with psychogenic polydipsia is optimally managed with behavioral treatments including fluid restriction (Dundas et al., 2007) and removal of, if identified, underlying causes. Careful monitoring of diurnal body weight change for the PIP syndrome patients is useful to recognize hyponatremic episodes at an earlier stage and prevent sequelae due to severe hyponatremic encephalopathy (Leadbetter et al., 1994). In any case, osmotic demyelination, such as central pontine myelinolysis, possibly associated with overaggressive correction of serum sodium concentrations (more than $10 \mathrm{mmol} / \mathrm{L}$ in 24 hours, $18 \mathrm{mmol} / \mathrm{L}$ in 48 hours, and $20 \mathrm{mmol} / \mathrm{L}$ in 72 hours), should be avoided (Sterns et al., 2009). Specific pharmacological treatment with democlocycline or AVP receptor antagonists (aquaretics) for chronic hyponatremia in psychiatric patients may become standardized in the near future (Siegel, 2008).

\subsection{Valproate-induced hyperammonemic encephalopathy}

It has been known that valproic acid occasionally induces hyperammonemic encephalopathy in patients with otherwise normal hepatic function (Carr \& Shrewsbury, 2007; Marie-José, 2007). In most cases, encephalopathic symptoms appear in a few days after 
initiation of valproate therapy, with exceptional case reports with onset after longer therapeutic periods for several months or years. There remains controversy as to whether symptoms have any relationship to daily dose or plasma concentration of valproic acid. In a prospective study, the significantly higher prevalence of asymptomatic hyperammonemia was found in the psychiatric patients treated with valproate than in the control, and there was a positive correlation between serum valproic acid concentrations and ammonia levels (Raja \& Azzoni, 2002). Nevertheless, it should be noted that many cases with symptomatic encephalopathic symptoms reported up to date have serum valproic acid concentrations within therapeutic range (Carr \& Shrewsbury, 2007; Marie-José, 2007).

\subsection{Transient splenial lesion of the corpus callosum}

Since several antiepileptic drugs have been widely prescribed as effective mood stabilizers in psychiatric practice (Grunze, 2010), all psychiatrists should be familiar with adverse phenomena associated with them. With widespread use of magnetic resonance imaging (MRI), a characteristic discrete focal lesion limited to the central area of the splenium of the corpus callosum has been recognized to occur in epileptic patients receiving antiepileptic drugs (S.S. Kim et al., 1999; Polster et al., 2001). Although the pathophysiological mechanisms of this lesion are still obscure, antiepileptics appear to be implicated as pathogenetic or triggering factors at least in some cases. Indeed, the same lesion has been reported also in the non-epileptic patients treated with antiepileptic drugs (Maeda et al., 2003; Honda et al., 2006). Some patients developed the lesion on treatment with antiepileptic drugs (Kim et al., 1999; Polster et al., 2001; Maeda et al., 2003), while others subsequent to withdrawal of them (Polster et al., 2001; Gürtler et al., 2005; Honda et al., 2006).

The lesion is usually detected accidentally by MRI, accompanied with no apparent clinical signs and symptoms. It is characterized with an isolated oval-shaped abnormal signal in MRI located in the central area of the splenium, no enhancement on post-contrast MRI, and complete reversibility without specific treatment. In consideration of its benign outcome, unnecessary invasive examination and therapeutic intervention should be avoided (Maeda et al., 2003).

\subsection{Miscellaneous}

Acute onset alterations in CNS function are derived from a variety of etiological factors. When specific pathogenetic processes directly invading the brain (e.g., vascular, infectious, and neoplastic diseases) are ruled out, other diffuse, multifocal, or metabolic causes should be considered (Posner et al., 2007). If treated with psychotropic drugs, the possibility of direct or indirect contribution of these chemicals to the pathophysiological status should be always evaluated with caution. The SIADH associated with psychotropic drugs and valproate-induced hyperammonemia, both of which have been described above, exemplify such implication. In addition, many psychotropic drugs, especially antidepressants and antipsychotics, have been shown to possess ability to reduce seizure threshold and to provoke epileptic seizures (Alldredge, 1999; Pisani et al., 2002). Antipsychotics, in particular atypical antipsychotics such as clozapine and olanzapine, are reported to be associated with an increased risk of obesity, diabetes, and metabolic syndrome (Scheen \& De Hert, 2007; Smith et al., 2008) and in the worse case it can result in fatal hyperglycemic encephalopathy (Koller \& Doraiswamy, 2002; Wehring et al., 2003). Lithium, a widely used mood stabilizer, 
increases the risk of hypothyroidism, which can range from subclinical to life-threatening myxedema coma (Bhuvaneswar et al., 2009; Thomas et al., 2010). A case of Hashimoto's encephalopathy possibly induced by lithium was also reported (Nagamine et al., 2008).

\section{Concluding remarks}

In these two decades, pharmacotherapy with psychotropic drugs for mentally ill patients has been dramatically changed. Classical prototypal antipsychotics, such as chlorpromazine and haloperidol, have been replaced with atypical antipsychotic drugs for the treatment of psychotic patients. As for the pharmacotherapy for mood disorders, total antidepressant prescribing has increased, especially in 1990s with exponential increase in prescriptions of SSRIs (Donoghue, 1998; Middleton, et al., 2001). This remarkable rise in SSRIs prescribing experienced in the United Kingdom may be attributable, in part, to the Defeat Depression Campaign (Paykel et al., 1997), which was undertaken from 1992 to 1996. However, the similar trends in antidepressant prescriptions have also been observed in all other developed countries worldwide. The vigorous marketing promoted by pharmaceutical companies probably contributed to the overwhelming spread of SSRIs in 1990s to a great extent (McHenry, 2005). In addition, SSRIs have been more and more prescribed not only for depression but also for a number of other psychiatric diagnoses such as anxiety, eating, impulse-control, and personality disorders. Many antiepileptic drugs are also prescribed generally for psychiatric patients in anticipation of their mood stabilizing effects.

In general, the newly developed psychotropic drugs are believed to be safer and more tolerable than older drugs. The apparent lowered risk of adverse effects of novel drugs may facilitate the clinician's attitude for prescribing these psychotropic drugs automatically, and sometimes indiscreetly. However, there is no efficacious drug without adverse side effects. All clinicians who have an occasion to prescribe psychotropic drugs, or to see the patients treated with them, should be familiar with adverse symptoms associated with them.

This chapter focuses on the adverse effects of psychotropic drugs involving altered CNS function. Although nonspecific CNS reaction due to overdosed psychotropic drugs has not been included, it should be always taken into consideration when the patients treated with psychotropic drugs exhibit inexplicable CNS symptoms. Lithium-induced toxic encephalopathy has been reported to occur even when serum lithium levels are kept within a therapeutic range (Sheean, 1991). When adverse effects on CNS function are presented apparently as psychiatric symptoms, these should not be misdiagnosed as exacerbation of the primary psychiatric disorder. Such misjudgment may lead to the clinical decision to increase the offending drugs or to add other kinds of psychotropic drugs, which could further complicate matters and delay appropriate intervention. Even in the case of the idiosyncratic adverse effects such as NMS, the most efficacious way to abort the syndrome without serious sequelae should be early recognition of, and prompt appropriate intervention in, the clinical symptoms at the incipient stage.

Pharmacotherapy becomes meaningfully efficacious only when it is considered in the whole therapeutic framework and associated synergistically with other psychosocial therapies. In general, most psychotropic drugs have only limited therapeutic effects, which never cure the psychiatric diseases themselves but relieve the symptoms partially. The efficacy of SSRIs in depressed patients over placebo has been shown to be minimal, if any, by recent meta- 
analyses (Moncrieff \& Kirsch, 2005). While it is true that pharmacotherapy bring enormous benefit to some patients, I have also been aware of many cases at a disadvantage associated with thoughtless or unnecessary use of psychotropic drugs. The prudent and conscientious decision-making for pharmacotherapy in consideration of the quality of life of the individual patient is highly warranted.

\section{Acknowledgment}

This review was envisioned while the author had been on loan to Moro Hospital, and was financially supported by the Grant for Research Work from the Saitama Medical University, Japan. The author is grateful to Professor Ryoichi Toyoshima, the chair of Department of Psychiatry, Faculty of Medicine, Saitama Medical University, and Dr. Taeko Maruki, the director of Moro Hospital, for their support and encouragement.

\section{References}

Adityanjee, Singh, S., Singh, G. \& Ong, S. (1988). Spectrum Concept of Neuroleptic Malignant Syndrome. British Journal of Psychiatry, Vol.153, (July 1988), pp. 107-111, ISSN 0007-1250

Adityanjee, Aderibigbe, Y.A. \& Mathews, T. (1999a). Epidemiology of Neuroleptic Malignant Syndrome. Clinical Neuropharmacology, Vol.22, No.3, (May/June 1999), pp. 151-158, ISSN 0362-5664

Adityanjee, Mathews, T. \& Aderibigbe, Y.A. (1999b). Proposed Research Diagnostic Criteria for Neuroleptic Malignant Syndrome. International Journal of Neuropsychopharmacolgy, Vol.2, No.2, (June 1999), pp. 129-144

Adityanjee, Sajatovic, M. \& Munshi, K.R. (2005). Neuropsychiatric Sequelae of Neuroleptic Malignant Syndrome. Clinical Neuropharmacology, Vol.28, No.4, (July/August 2005), pp. 197-204, ISSN 0362-5664

Addonizio, G., Susman, V.L. \& Roth, S.D. (1986). Symptoms of Neuroleptic Malignant Syndrome in 82 Consecutive Inpatients. American Journal of Psychiatry, Vol.143, No.12, (December 1986), pp. 1587-1590, ISSN 0002-953X

Addonizio, G., Susman, V.L. \& Roth, S.D. (1987). Neuroleptic Malignant Syndrome: Review and Analysis of 115 Cases. Biological Psychiatry, Vol.22, No.8, (August 1987), pp. 1004-1020, ISSN 0006-3223

Adrogué, H.J. (2005). Consequences of Inadequate Management of Hyponatremia. American Journal of Nephrology, Vol.25, No.3, (May/June 2005), pp. 240-249, ISSN 0250-8095

Alldredge, B.K. (1999). Seizure Risk Associated with Psychotropic Drugs: Clinical and Pharmacokinetic Considerations. Neurology, Vol.53, No.5, Suppl.2, (September 1999), pp. S68-S75, ISSN 0028-3878

Ananth, J., Aduri, K., Parameswaran, S. \& Gunatilake, S. (2004a). Neuroleptic Malignant Syndrome: Risk factors, Pathophysiology, and Treatment. Acta Neuropsychiatrica, Vol.16, No.4, (August 2004), pp. 219-228

Ananth, J., Parameswaran, S., Gunatilake, S., Burgoyne, K. \& Sidhom, T. (2004b). Neuroleptic Malignant Syndrome and Atypical Antipsychotic Drugs. Journal of Clinical Psychiatry, Vol.65, No.4, (April 2004), pp. 464-470, ISSN 0160-6689 
Andersen, H. \& Kristiansen, E.S. (1959). Tofranil-Treatment of Endogenous Depressions. Acta Psychiatrica et Neurologica Scandinavica, Vol.34, No.4, pp. 387-397, ISSN 0001690X

Asch, D.A. \& Parker, R.M. (1988). The Libby Zion Case. One Step Forward or Two Steps Backward? New England Journal of Medicine, Vol.318, No.12, (March 1988), pp. 771775, ISSN 0028-4793

Assion, H.J., Heinemann, F. \& Laux, G. (1998). Neuroleptic Malignant Syndrome under Treatment with Antidepressants? A Critical Review. European Archives of Psychiatry and Clinical Neuroscience, Vol.248, No.5, (October 1998), pp. 231-239, ISSN 0940-1334

Attar-Herzberg, D., Apel, A., Gang, N., Dvir, D. \& Mayan, H. (2009). The Serotonin Syndrome: Initial Misdiagnosis, Israel Medical Association Journal, Vol.11, No.6, (June 2009), pp. 367-370, ISSN 1565-1088

Berardi, D., Amore, M., Keck, P.E. Jr., Troia, M. \& Dell'Atti, M. (1998). Clinical and Pharmacologic Risk Factors for Neuroleptic Malignant Syndrome: A Case-Control Study. Biological Psychiatry, Vol.44, No.8, (October 1998), pp. 748-754, ISSN 00063223

Bhuvaneswar, C.G., Baldessarini, R.J., Harsh, V.L. \& Alpert, J.E. (2009). Adverse Endocrine and Metabolic Effects of Psychotropic Drugs. CNS Drugs, Vol.23, No.12, (December 2009), pp. 1003-1021, ISSN 1172-7047

Black, K., Shea, C., Dursun, S. \& Kutcher, S. (2000). Selective Serotonin Reuptake Inhibitor Discontinuation Syndrome: Proposed Diagnostic Criteria. Journal of Psychiatry and Neuroscience, Vol.25, No.3, (May 2000), pp. 255-261, ISSN 1180-4882

Boyer, E.W. \& Shannon, M. (2005). The Serotonin Syndrome. New England Journal of Medicine, Vol.352, No.11, (May 2005), pp. 1112-1120, ISSN 0028-4793

Brennan, D., MacManus, M., Howe, J. \& McLoughlin, J. (1988). 'Neuroleptic Malignant Syndrome' without Neuroleptics. British Journal of Psychiatry, Vol.152, No.4, (April 1988), pp. 578-579, ISSN 0007-1250

Caroff, S.N. (1980). The Neuroleptic Malignant Syndrome. Journal of Clinical Psychiatry, Vol.41, No.3, (March 1980), pp. 79-83, ISSN 0160-6689

Caroff, S.N. \& Mann, S.C. (1988). Neuroleptic Malignant Syndrome. Psychopharmacology Bulletin, Vol.24, No.1, pp. 25-29, ISSN 0048-5764

Caroff, S.N. \& Mann, S.C. (1993). Neuroleptic Malignant Syndrome. Medical Clinics of North America, Vol.77, No.1, (January 1993), pp. 185-202, ISSN 0025-7125

Caroff, S.N., Mann, S.C., Lazarus, A., Sullivan, K. \& MacFadden, W. (1991). Neuroleptic Malignant Syndrome: Diagnostic Issues. Psychiatric Annals, Vol.21, No.3, (March 1991), pp. 130-147

Caroff, S.N., Mann, S.C. \& Campbell, E.C. (2000). Atypical Antipsychotics and Neuroleptic Malignant Syndrome. Psychiatric Annals, Vol.30, No.5, (May 2000), pp. 314-321

Caroll, B.T. \& Taylor, R.E. (1997). The Nondichotomy between Lethal Catatonia and Neuroleptic Malignant Syndrome. Journal of Clinical Psychopharmacology, Vol.17, No.3, (June 1997), pp. 235-236, ISSN 0271-0749

Carr, R.B. \& Shrewsbury, K. (2007). Hyperammonemia Due to Valproic Acid in the Psychiatric Setting. American Journal of Psychiatry, Vol.164, No.7, (July 2007), pp. 1020-1027, ISSN 0002-953X 
Castillo, E., Rubin, R.T., Holsboer-Trachsler, E. (1989). Clinical Differentiation between Lethal Catatonia and Neuroleptic Malignant Syndrome. American Journal of Psychiatry, Vol.146, No.3, (March 1989), pp. 324-328, ISSN 0002-953X

Chan-Tack, K.M. (1999) Neuroleptic Malignant Syndrome Due to Promethazine. Southern Medical Journal, Vol.92, No.10, (October 1999), pp. 1017-1018, ISSN 0038-4348

Cooper, G.L. (1988). The Safety of Fluoxetine - An Update. British Journal of Psychiatry, Vol.153, Suppl.3, (September 1988), pp. 77-86, ISSN 0960-5371

Coupland, N., Bell, C.J. \& Potokar, J.P. (1996). Serotonin Reuptake Inhibitor Withdrawal. Journal of Clinical Psychopharmacology, Vol.16, No.5, (October 1996), pp. 356-362, ISSN 0271-0749

Davis, J.M., Janicak, P.G., Sakkas, P., Gilmore, C. \& Wang, Z. (1991). Electroconvulsive Therapy in the Treatment of the Neuroleptic Malignant Syndrome. Convulsive Therapy, Vol.7, No.2, (June 1991), pp. 111-120, ISSN 0749-8055

Davis, J.M., Caroff, S.N. \& Mann, S.C. (2000). Treatment of Neuroleptic Malignant Syndrome. Psychiatric Annals, Vol. 30, No.5, (May 2000), pp. 325-331

Delay, J. \& Deniker, P. (1968). Drug-induced Extrapyramidal Syndromes, In: Handbook of Clinical Neurology, Vol.6, Diseases of the Basal Ganglia, P.J. Vinken \& O.W. Bruyn, (Eds.), pp. 248-266, Elsevier, New York, USA

De Leon, J., Verghese, C., Tracy, J.I., Josiassen, R.C. \& Simpson, G.M. (1994). Polydipsia and Water Intoxication in Psychiatric Patients: A Review of the Epidemiological Literature. Biological Psychiatry, Vol.35, No.6, (March 1994), pp. 408-419, ISSN 00063223

Deuschl, G., Oepen, G., Hermie, L. \& Kindt, H. (1987). Neuroleptic Malignant Syndrome: Observations on Altered Consciousness. Pharmacopsychiatry, Vol.20, No.4, (July 1987), pp. 168-170, ISSN 0176-3679

Dike, G.L. (1997). Triphasic Waves in Serotonin Syndrome. Journal of Neurology, Neurosurgery, and Psychiatry, Vol.62, No.2, (February 1997), pp. 200, ISSN 0022-3050

Dilsaver, S.C. \& Greden, J.F. (1984). Antidepressant Withdrawal Phenomena. Biological Psychiatry, Vol.19, No.2, (February 1984), pp. 237-256, ISSN 0006-3223

Dilsaver, S.C., Greden, J.F. \& Snider, R.M. (1987). Antidepressant Withdrawal Syndromes: Phenomenology and Pathophysiology. International Clinical Psychopharmacology, Vol.2, No.1, (January 1987), pp. 1-19, ISSN 0268-1315

Donoghue, J. (1998) Selective Serotonin Reuptake Inhibitor Use in Primary Care. A 5-Year Naturalistic Study. CNS Drug Investigation, Vol.16, No.6, (December 1998), pp. $453-$ 462, ISSN 1173-2563

Dundas, B., Harris, M. \& Narasimban, M. (2007). Psychogenic Polydipsia Review: Etiology, Differential, and Treatment. Current Psychiatry Reports, Vol.9, No.3, (June 2007), pp. 236-241, ISSN 1523-3812

Dunkley, E.J.C., Isbister, G.K., Sibbritt, D., Dawson, A.H. \& Whyte, I.M. (2003). The Hunter Serotonin Toxicity Criteria: Simple and Accurate Diagnostic Decision Rules for Serotonin Toxicity. QJM, Vol.96, No.9, (September 2003), pp. 635-642, ISSN 14602725

Einbinder, E. (1995). Fluoxetine Withdrawal? American Journal of Psychiatry, Vol.152, No.8, (August 1995), pp. 1235, ISSN 0002-953X

Farver, D.K. (2003). Neuroleptic Malignant Syndrome Induced by Atypical Antipsychotics. Expert Opinion on Drug Safety, Vol.2, No.1, (January 2003), pp. 21-35, ISSN 1474-0338 
Feibel, J.H. \& Schiffer, R.B. (1981). Sympthoadrenomedullary Hyperactivity in the Neuroleptic Malignant Syndrome: A Case Report. American Journal of Psychiatry, Vol.138, No.8, (August 1981), pp. 1115-1116, ISSN 0002-953X

Fink, M. (1996a). Neuroleptic Malignant Syndrome and Catatonia: One Entity or Two? Biological Psychiatry, Vol.39, No.1, (January 1996), pp. 1-4, ISSN 0006-3223

Fink, M. (1996b). Toxic Serotonin Syndrome or Neuroleptic Malignant Syndrome? Pharmacopsychiatry, Vol.29, No.4, (July 1996), pp. 159-161, ISSN 0176-3679

Fitzgerald, B., Middleton, J.K. \& Cooper, S.A. (1997). Adverse Effects of Summer amongst People with Learning Disabilities: Neuroleptic Malignant Syndrome. Journal of Intellectual Disability Research, Vol.41, No.3, (June 1997), pp. 273-277, ISSN 0964-2633

Frances, A., Pincus, H.A. \& First, M.B. (2000). Neuroleptic Malignant Syndrome, In: Diagnostic and Statistical Manual of Mental Disorders, Fourth Edition, Text Revision (DSM-IV-TR), American Psychiatric Association (Ed.), pp. 795-798, ISBN 0-89042024-6, Washington, DC

Francis, A., Chandragiri, S., Rizvi, S., Koch, M. \& Petrides, G. (2000). Is Lorazepam a Treatment for Neuroleptic Malignant Syndrome? CNS Spectrum, Vol.5, No.7, (July 2000), pp. 54-57, ISSN 1092-8529

Fraser, C.L. \& Arieff, A.I. (1997). Epidemiology, Pathophysiology, and Management of Hyponatremic Encephalopathy. American Journal of Medicine, Vol.102, No.1, (January 1997), pp. 67-77, ISSN 0002-9343

Fricchione, G., Mann, S.C. \& Caroff, S.N. (2000). Catatonia, Lethal Catatonia, and Neuroleptic Malignant Syndrome. Psychiatric Annals, Vol.30, No.5, (May 2000), pp. 347-355

Friedman, J.H., Feinberg, S.S. \& Friedman, R.G. (1985). A Neuroleptic Malignantlike Syndrome due to Levodopa Therapy Withdrawal. JAMA, Vol.254, No.19, (November 1985), pp. 2792-2795, ISSN 0098-7484

Friedman, J.H., Davis, R. \& Wagner, R.L. (1988). Neuroleptic Malignant Syndrome. The Results of a 6-Month Prospective Study of Incidence in a State Psychiatric Hospital. Clinical Neuropharmacolgy, Vol.11, No.4, (August 1988), pp. 373-377, ISSN 0362-5664

Friedman, L.S., Weinrauch, L.A. \& D’Elia, J.A. (1987). Metoclopramide-Induced Neuroleptic Malignant Syndrome. Archives of Internal Medicine, Vol.147, No.8, (August 1987), pp. 1495-1497, ISSN 0003-9926

Gerson, S.C. \& Baldessarini, R.J. (1980). Motor Effects of Serotonin in the Central Nervous System. Life Sciences, Vol.27, No.16, (October 1980), pp. 1435-1451, ISSN 0024-3205

Gillman, P.K. (1998). Serotonin Syndrome: History and Risk. Fundamental and Clinical Pharmacology, Vol.12, No.5, (September/October 1998), pp. 482-491, ISSN 0767-3981

Gillman, P.K. (1999). The Serotonin Syndrome and Its Treatment. Journal of Psychopharmacology, Vol.13, No.1, (January 1999), pp. 100-109, ISSN 0269-8811

Gillman, P.K. (2006). A Review of Serotonin Toxicity Data: Implications for the Mechanisms of Antidepressant Drug Action. Biological Psychiatry, Vol.59, No.11, (June 2006), pp. 1046-1051, ISSN 0006-3223

Goldman, M.B., Luchins, D.J. \& Robertson, G.L. (1988). Mechanisms of Altered Water Metabolism in Psychotic Patients with Polydipsia and Hyponatremia. New England Journal of Medicine, Vol.318, Vol.7, (February 1998), pp. 397-403, ISSN 0028-4793 
Goldman, M.B., Robertson, G.L., Luchins, D.J., Hedeker, D. \& Pandey, G.N. (1997). Psychotic Exacerbations and Enhanced Vasopressin Secretion in Schizophrenic Patients with Hyponatremia and Polydipsia. Archives of General Psychiatry, Vol.54, No.5, (May 1997), pp. 443-449, ISSN 0003-990X

Grunze, H.C.R. (2010). Anticonvulsants in Bipolar Disorder. Journal of Mental Health, Vol.19, No.2, (April 2010), pp. 127-141, ISSN 0963-8237

Gurrera, R.J. (1999). Sympathoadrenal Hyperactivity and the Etiology of Neuroleptic Malignant Syndrome. American Journal of Psychiatry, Vol.156, No.2, (February 1999), pp. 169-180, ISSN 0002-953X

Gurrera, R.J. \& Romero, J.A. (1992). Sympathoadrenomedullary Activity in the Neuroleptic Malignant Syndrome. Biological Psychiatry, Vol.32, No.4, (August 1992), pp. 334-343, ISSN 0006-3223

Gürtler, S., Ebner, A., Tuxhorn, I., Ollech, I., Pohlmann-Eden, B. \& Woermann, F.G. (2005). Transient Lesion in the Splenium of the Corpus Callosum and Antiepileptic Drug Withdrawal. Neurology, Vol.65, No.7, (October 2005), pp. 1032-1036, ISSN 0028-3878

Haddad, P. (1997). Newer Antidepressants and the Discontinuation Syndrome. Journal of Clinical Psychiatry, Vol.58, Suppl.7, pp. 17-22, ISSN 0160-6689

Haddad, P. (1998). The SSRI Discontinuation Syndrome. Journal of Psychopharmacology, Vol.12, No.3, (May 1998), pp. 305-313, ISSN 0269-8811

Harris, M., Nora, L., Tanner, C.M. (1987). Neuroleptic Malignant Syndrome Responsive to Carbidopa/Levodopa: Support for a Dopaminergic Pathogenesis. Clinical Neuropharmacology, Vol.10, No.2, (April 1987), pp. 186-189, ISSN 0362-5664

Hegerl, U., Bottlender, R., Gallinat, J., Kuss, H.-J., Ackenheil, M. \& Möller, H.-J. (1998). The Serotonin Syndrome Scale: First Results on Validity. European Archives of Psychiatry and Clinical Neuroscience, Vol.248, No.2, (May 1998), pp. 96-103, ISSN 0940-1334

Henderson, V.W. \& Wooten, G.F. (1981). Neuroleptic Malignant Syndrome: A Pathogenetic Role for Dopamine Receptor Blockade? Neurology, Vol.31, No.2, (February 1981), pp. 132-137, ISSN 0028-3878

Hermesh, H., Manor, I., Shiloh, R., Aizenberg, D. Benjamini, Y., Munitz, H. \& Weizman, A. (2002). High Serum Creatinin Kinase Level: Possible Risk Factor for Neuroleptic Malignant Syndrome. Journal of Clinical Psychopharmacology, Vol.22, No.3, (June 2002), pp. 252-256, ISSN 0271-0749

Hernández, J.L., Ramos, F.J., Infante, J., Rebollo, M. \& González-Macías, J. (2002). Severe Serotonin Syndrome Induced by Mirtazapine Monotherapy. Annals of Pharmacotherapy, Vol.36, No.4, (April 2002), pp. 641-643, ISSN 1060-0280

Heyland, D. \& Sauvé, M. (1991). Neuroleptic Malignant Syndrome without the Use of Neuroleptics. Canadian Medical Association Journal, Vol.145, No.7, (October 1991), pp. 817-819, ISSN 0820-3946

Honda, K., Nishimiya, J., Sato, H., Munakata, M., Kamada, M., Iwamura, A., Nemoto, H., Sakamoto, T. \& Yuasa, T. (2006). Transient Splenial Lesion of the Corpus Callosum after Acute Withdrawal of Antiepileptic Drug: A Case Report. Magnetic Resonance in Medical Sciences, Vol.5, No.4, (December 2006), pp. 211-215, ISSN 1347-3182

Insel, T.R., Roy, B.F., Cohen, R.M. \& Murphy, D.L. (1982). Possible Development of the Serotonin Syndrome in Man. American Journal of Psychiatry, Vol.139, No.7, (July 1982), pp. 954-955, ISSN 0002-953X 
Isbister, G.K. \& Buckley, N.A. (2005). The Pathophysiology of Serotonin Toxicity in Animals and Humans. Clinical Neuropharmacology, Vol.28, No.5, (September/October 2005), pp. 205-214, ISSN 0362-5664

Jacobs, B.L. (1976). An Animal Behavior Model for Studying Central Serotonergic Synapses. Life Sciences, Vol.19, No.6, (September 1976), pp. 777-786, ISSN 0024-3205

Kaplan, E.M. (1997). Antidepressant Noncompliance as a Factor in the Discontinuation Syndrome. Journal of Clinical Psychiatry, Vol.58, Suppl.7, pp. 31-36, ISSN 0160-6689

Keck, P.E. Jr., Arnold, L.M. (2000). The Serotonin Syndrome. Psychiatric Annals, Vol.30, No.5, (May 2000), pp. 333-343

Keck, P.E. Jr., Pope, H.G. Jr., Cohen, B.M., McElroy, S.L. \& Nierenberg, A.A. (1989a). Risk Factors for Neuroleptic Malignant Syndrome. A Case-Control Study. Archives of General Psychiatry, Vol.46, No.10, (October 1989), pp. 914-918, ISSN 0003-990X

Keck, P.E. Jr., Sebastianelli, J., Pope, H.G. Jr. \& McElroy, S.L. (1989b). Frequency and Presentation of Neuroleptic Malignant Syndrome in a State Psychiatric Hospital. Journal of Clinical Psychiatry, Vol.50, No.9, (September 1989), pp. 352-355, ISSN 01606689

Keck, P.E. Jr., McElroy, S.L. \& Pope, H.G. Jr. (1991). Epidemiology of Neuroleptic Malignant Syndrome. Psychiatric Annals, Vol.21, No.3, (March 1991), pp. 148-151

Kellam, A.M.P. (1987a). The Neuroleptic Malignant Syndrome, So-called. A Survey of the World Literature. British Journal of Psychiatry, Vol.150, (June 1987), pp. 752-759, ISSN 0007-1250

Kellam, A.M.P. (1987b). Correspondence. British Journal of Psychiatry, Vol.151, No.6, (December 1987), pp. 864-865

Kim, J.-M., Lee, S.-T., Song, E.-C., Jung, K.-H., Sinn, D.-I., Chung, H., Chu, K. \& Kim, M. (2007). Neurotoxic Syndrome Developed after Taking Sertraline and Risperidone. Journal of Clinical Neurology, Vol.3, No.3, (September 2007), pp. 165-167, ISSN 17386586

Kim, S.S., Chang, K.-H., Kim, S.T., Suh, D.C., Cheon, J.-E., Jeong, S.-W., Han, M.H. \& Lee, S.K. (1999). Focal Lesion in the Splenium of the Corpus Callosum in Epileptic Patients: Antiepileptic Drug Toxicity? American Journal of Neuroradiology, Vol.20, No.1, (January 1999), pp. 125-129, ISSN 0195-6108

Kinross-Wright, J.V. (1958). Trifluoperazine and Schizophrenia, In: Trifluoperazine. Clinical and Pharmacological Aspects, H. Brill, (Ed.), pp. 62-70, Lea and Febiger, Philadelphia, USA

Koller, E.A. \& Doraiswamy, P.M. (2002). Olanzapine-Associated Diabetes Mellitus. Pharmacotherapy, Vol.22, No.7, (July 2002), pp. 841-852, ISSN 0277-0008

Kontaxakis, V.P., Havaki-kontaxaki, B.J., Christodoulou N.G., Paplos, K.G. \& Christodoulou, G.N. (2003). Olanzapine-Associated Neuroleptic Malignant Syndrome: Is There an Overlap with the Serotonin Syndrome? Annals of General Hospital Psychiatry, Vol.2, No.1, (October 2003), pp. 10, ISSN 1475-2832, Available from http:/ / www.general-hospital-psychiatry.com/content/2/1/10/

Kurlan, R., Hamill, R. \& Shoulson, I. (1984). Neuroleptic Malignant Syndrome. Clinical Neuropharmacology, Vol.7, No.2, (June 1984), pp.109-120, ISSN 0362-5664

Leadbetter, R.A., Shutty, M.S. Jr., Higgins, P.B. \& Pavalonis, D. (1994). Multidisciplinary Approach to Psychosis, Intermittent Hyponatremia, and Polydipsia. Schizophrenia Bulletin, Vol.20, No.2, pp. 375-385, ISSN 0586-7614 
Lejoyeux, M., Fineyre, F. \& Adès, J. (1992). The Serotonin Syndrome. American Journal of Psychiatry, Vol.149, No.10, (October 1992), pp. 1410-1411, ISSN 0002-953X

Lejoyeux, M., Adès, J., Mourad, I., Solomon, J. \& Dilsaver, S. (1996). Antidepressant Withdrawal Syndrome. Recognition, Prevention and Management. CNS Drugs, Vol.5, No.4, (April 1996), pp. 278-292, ISSN 1172-7047

Levenson, J.L. (1985). Neuroleptic Malignant Syndrome. American Journal of Psychiatry, Vol.142, No.10, (October 1985), pp. 1137-1145, ISSN 0002-953X

MacKay, F.J., Dunn, N.R. \& Mann, R.D. (1999). Antidepressants and the Serotonin Syndrome in General Practice. British Journal of General Practice, Vol.49, No.448, (November 1999), pp. 871-874, ISSN 0960-1643

Madakasira, S. (1989). Amoxapine-Induced Neuroleptic Malignant Syndrome. DICP, Annals of Pharmacotherapy, Vol.23, No.1, (January 1989), pp. 50-55, ISSN 1042-9611

Maeda, M., Shiroyama, T., Tsukahara, H., Shimono, T., Aoki, S. \& Takeda, K. (2003). Transient Splenial Lesion of the Corpus Callosum Associated with Antiepileptic Drugs: Evaluation by Diffusion-Weighted MR Imaging. European Radiology, Vol.13, No.8, (August 2003), pp. 1902-1906, ISSN 0938-7994

Mann, S.C., Caroff, S.N., Bleier, H.R., Welz, W.K.R., Kling, M.A. \& Hayashida, M. (1986). Lethal Catatonia, American Journal of Psychiatry, Vol.143, No.11, (November 1986), pp. 1374-1381, ISSN 0002-953X

Mann, S.C., Caroff, S.N., Fricchione, G. \& Campbell, E.C. (2000). Central Dopamine Hypoactivity and the Pathogenesis of Neuroleptic Malignant Syndrome. Psychiatric Annals, Vol.30, No.5, (May 2000), pp. 363-374

Marie-José, C.C.D. Valproate-Induced Hyperammonaemic Encephalopathy: Review of 14 Cases in the Psychiatric Setting. (2007). International Clinical Pshychopharmacology, Vol.22, No, 6, (November 2007), pp. 330-337, ISSN 0268-1315

Mason, P.J., Morris, V.A. \& Balcezak, T.J. (2000). Serotonin Syndrome: Presentation of 2 Cases and Review of the Literature. Medicine, Vol.79, No.4, (July 2000), pp. 201-209, ISSN 0025-7974

McHenry, L. (2006). Ethical Issues in Psychopharmacology. Journal of Medical Ethics, Vol.32, No.7, (July 2006), pp. 405-410, ISSN 0306-6800

Meulendijks, D., Mannesse, C.K., Jansen, P.A.F., van Marum, R.J. \& Egberts, T.C.G. (2010). Antipsychotic-Induced Hyponatremia. Drug Safety, Vol. 33, No.2, (February 2010), pp. 101-14, ISSN 0114-5916

Middleton, N., Gunnell, D., Whitley, E., Dorling, D. \& Frankel, S. (2001). Secular Trends in Antidepressant Prescribing in the UK, 1975-1998. Journal of Public Health Medicine, Vol.23, No.4, (December 2001), pp. 262-267, ISSN 0957-4832

Mills, K.C. (1995). Serotonin Syndrome. American Family Physician, Vol.52, No.5, (October 1995), pp. 1475-1482, ISSN 0002-838X

Mills, K.C. (1997). Serotonin Syndrome. Critical Care Clinics, Vol.13, No.4, (October 1997), pp. 763-783, ISSN 0749-0704

Mitchell, R.S. (1955). Fatal Toxic Encephalitis Occurring during Iproniazid Therapy in Pulmonary Tuberculosis. Annals of Internal Medicine, Vol.42, No.2, (February 1955), pp. 417-424, ISSN 0003-4819

Moncrieff, J. \& Kirsch, I. (2005). Efficacy of Antidepressants in Adults. British Medical Journal, Vol.331(7509), (July 2005), pp. 155-157, ISSN 0959-535X 
Montoya, A., Ocampo, M. \& Torres-Ruiz, A. (2003). Neuroleptic Malignant Syndrome in Mexico. Canadian Journal of Clinical Pharmacology, Vol.10, No.3, (Autumn 2003), pp. 111-113, ISSN 1198-581X

Nagamine, M. Yoshino, A., Ishii, M., Ogawa, T., Kurauchi, S., Yoshida, T., Shigemura, J., Kodera, T., Tanaka, Y. \& Nomura, S. (2008). Lithium-Induced Hashimoto's Encephalopathy: A Case Report. Bipolar Disorders, Vol.10, No.7, (November 2008), pp. 846-848, ISSN 1398-5647

Nierenberg, D., Disch, M., Manheimer, E., Patterson, J., Ross, J., Silvestri, G. \& Summerhill, E. (1991). Facilitating Prompt Diagnosis and Treatment of the Neuroleptic Malignant Syndrome. Clinical Pharmacology and Therapeutics, Vol.50, No.5, (November 1991), pp. 580-586, ISSN 0009-9236

Nisijima, K., Noguti, M. \& Ishiguro, T. (1997). Intravenous Injection of Levodopa Is More Effective Than Dantrolene as Therapy for Neuroleptic Malignant Syndrome. Biological Psychiatry, Vol.41, No.8, (April 1997), pp. 913-914, ISSN 0006-3223

Nisijima, K., Shioda, K. \& Iwamura, T. (2007). Neuroleptic Malignant Syndrome and Serotonin Syndrome, Progress in Brain Research, Vol.162, pp. 81-104, ISSN 0079-6123

Northhoff, G. (1996). Neuroleptic Malignant Syndrome and Catatonia: One Entity or Two? Biological Psychiatry, Vol.40, No.5, (September 1996), pp. 431-432, ISSN 0006-3223

Odagaki, Y. (2009). Atypical Neuroleptic Malignant Syndrome or Serotonin Toxicity Associated with Atypical Antipsychotics? Current Drug Safety, Vol.4, No.1, 84-93, (January 2009), pp. 84-93, ISSN 1574-8863

Otani, K., Horiuchi, M., Kondo, T., Kaneko, S. \& Fukushima, Y. (1991). Is the Predisposition to Neuroleptic Malignant Syndrome Genetically Transmitted? British Journal of Psychiatry, Vol.158, No.6, (June 1991), pp. 850-853, ISSN 0007-1250

Paykel, E.S., Tylee, A., Wright, A., Priest, R.G., Rix, S. \& Hart, D. (1997). The Defeat Depression Campaign: Psychiatry in the Public Arena. American Journal of Psychiatry, Vol.154, No.6, Festschrift Suppl., (June 1997), pp. 59-65, ISSN 0002-953X

Picard, L.S., Lindsay, S., Strawn, J.R., Kaneria, R.M., Patel, N.C. \& Keck, P.E. Jr. (2008). Atypical Neuroleptic Malignant Syndrome: Diagnostic Controversies and Considerations. Pharmacopsychiatry, Vol.28, No.4, (April 2008), pp. 530-535, ISSN 0277-0008

Pisani, F., Oteri, G., Costa, C., Di Raimondo, G. \& Di Perri, R. (2002). Effects of Psychotropic Drugs on Seizure Threshold. Drug Safety, Vol.25, No.2, pp. 91-110, ISSN 0114-5916

Polster, T., Hoppe, M. \& Ebner, A. (2001). Transient Lesion in the Splenium of the Corpus Callosum: Three Further Cases in Epileptic Patients and a Pathophysiological Hypothesis. Journal of Neurology, Neurosurgery, and Psychiatry, Vol.70, No.4, (April 2001), pp. 459-463, ISSN 0022-3050

Pope, H.G. Jr., Keck, P.E. \& McElroy, S.L. (1986). Frequency and Presentation of Neuroleptic Malignant Syndrome in a Large Psychiatric Hospital. American Journal of Psychiatry, Vol. 143, No.10, (October 1986), pp. 1227-1233, ISSN 0002-953X

Posner, J.B., Saper, C.B., Schiff, N.D. \& Plum, F. (Eds.). (2007). Plum and Posner's Diagnosis of Stupor and Coma, Oxford University Press, ISBN 978-0-19-532131-9, New York, USA

Preston, J. (1959). Central Nervous System Reactions to Small Doses of Tranquilizers. Report of One Death. American Practitioner and Digest of Treatment, Vo10, No.4, (April 1959), pp. 627-630 
Price, J.S., Waller, P.C., Wood, S.M. \& MacKay, A.V.P. (1996). A Comparison of the PostMarketing Safety of Four Selective Serotonin Re-Uptake Inhibitors Including the Investigation of Symptoms Occurring on Withdrawal. British Journal of Clinical Pharmacology, Vol.42, No.6, (December 1996), pp. 757-763, ISSN 0306-5251

Radomski, J.W., Dursun, S.M., Reveley, M.A. \& Kutcher, S.P. (2000). An Exploratory Approach to the Serotonin Syndrome: An Update of Clinical Phenomenology and Revised Diagnostic Criteria. Medical Hypotheses, Vol.55, No.3, (September 2000), pp. 218-224, ISSN 0306-9877

Raja, M. \& Azzoni, A. (2002). Valproate-Induced Hyperammonaemia. Journal of Clinical Psychopharmacology, Vol.22, No.6, (December 2002), pp. 631-633, ISSN 0271-0749

Reddy, P. \& Mooradian, A.D. (2009). Diagnosis and Management of Hyponatremia in Hospitalised Patients. International Journal of Clinical Practice, Vol.63, No.10, (October 2009), pp. 1494-1508, ISSN 1368-5031

Reulbach, U., Dutsch, C., Biermann, T., Sperling, W., Thuerauf, N., Kornhuber, J. \& Bleich, S. Managing an Effective Treatment for Neuroleptic Malignant Syndrome. Critical Care, Vol.11, No.1, (January 2007), pp. R4, ISSN 1364-8535, Available from http://ccforum.com/content/11/1/R4

Riggs, A.T., Dysken, M.W., Kim, S.W. \& Opsahl, J.A. (1991). A Review of Disorders of Water Homeostasis in Psychiatric Patients. Psychosomatics, Vol.32, No.2, (Spring 1991), pp. 133-148, ISSN 0033-3182

Robinson, M.B., Kennett, R.P., Harding, A.E., Legg, N.J. \& Clarke, B. (1985). Neuroleptic Malignant Syndrome Associated with Metoclopramide. Journal of Neurology, Neurosurgery, and Psychiatry, Vol.48, No.12, (December 1985), pp. 1304, ISSN 0022-3050

Rosebush, P. \& Stewart, T. (1989). A Prospective Analysis of 24 Episodes of Neuroleptic Malignant Syndrome. American Journal of Psychiatry, Vol.146, No.6, (June 1989), pp. 717-725, ISSN 0002-953X

Rosebush, P.I., Stewart, T. \& Mazurek, M.F. (1991). The Treatment of Neuroleptic Malignant Syndrome. Are Dantrolene and Bromocriptine Useful Adjuncts to Supportive Care? British Journal of Psychiatry, Vol.159, No.5, (November 1991), pp. 709-712, ISSN 0007-1250

Rosenbaum, J.F. \& Zajecka, J. (1997). Clinical Management of Antidepressant Discontinuation. Journal of Clinical Psychiatry, Vol.58, Suppl.7, pp. 37-40, ISSN 01606689

Rosenbaum, J.F., Fava, M., Hoog, S.L., Ascroft, R.C. \& Krebs, W.B. (1998). Selective Serotonin Reuptake Inhibitor Discontinuation Syndrome: A Randomized Clinical Trial. Biological Psychiatry, Vol.44, No.2, (July 1998), pp. 77-87, ISSN 0006-3223

Rosenberg, M.R. \& Green, M. (1989). Neuroleptic Malignant Syndrome. Review of Response to Therapy. Archives of Internal Medicine, Vol.149, No.9, (September 1989), pp. 19271931, ISSN 0003-9926

Sakkas, P., Davis, J.M., Hua, J. \& Wang, Z. (1991a). Pharmacotherapy of Neuroleptic Malignant Syndrome. Psychiatric Annals, Vol.21, No.3, (March 1991), pp. 157-164

Sakkas, P., Davis, J .M., Janicak, P. G. \& Wang, Z. Y. (1991b) Drug Treatment of the Neuroleptic Malignant Syndrome. Psychopharmacology Bulletin, Vol.27, No.3, pp. 381-384, ISSN 0048-5764 
Schatzberg, A.F., Haddad, C.P., Kaplan, E.M., Lejoyeux, M., Rosenbaum, J.F., Young, A.H. \& Zajecka, J. (1997a). Possible Biological Mechanisms of the Serotonin Reuptake Inhibitor Discontinuation Syndrome. Journal of Clinical Psychiatry, Vol.58, Suppl.7, pp. 23-27, ISSN 0160-6689

Schatzberg, A.F., Haddad, C.P., Kaplan, E.M., Lejoyeux, M., Rosenbaum, J.F., Young, A.H. \& Zajecka, J. (1997b). Serotonin Reuptake Inhibitors Discontinuation Syndrome: A Hypothetical Definition. Journal of Clinical Psychiatry, Vol.58, Suppl.7, pp. 5-10, ISSN 0160-6689

Scheen, A.J. \& De Hert, M.A. (2007). Abnormal Glucose Metabolism in Patients Treated with Antipsychotics. Diabetes and Metabolism, Vol.33, No.3, (June 2007), pp. 169-175, ISSN 1262-3636

Serrano-Dueñas, M. (2003). Neuroleptic Malignant Syndrome-Like, or - Dopaminergic Malignant Syndrome - Due to Levodopa Therapy Withdrawal. Clinical Features in 11 Patients. Parkinsonism and Related Disorders, Vol.9, No.3, (January 2003), pp. 175178, ISSN 1353-8020

Shalev, A. \& Munitz, H. (1986). The Neuroleptic Malignant Syndrome: Agent and Host Interaction. Acta Psychiatrica Scandinavica, Vol.73, No.4, (April 1986), pp. 337-347, ISSN 0001-690X

Shalev, A., Hermesh, H. \& Munitz, H. (1988). The Role of External Heat Load in Triggering the Neuroleptic Malignant Syndrome. American Journal of Psychiatry, Vol.145, No.1, (January 1988), pp. 110-111, ISSN 0002-953X

Shalev, A., Hermesh, H. \& Munitz, H. (1989). Mortality from Neuroleptic Malignant Syndrome. Journal of Clinical Psychiatry, Vol.50, No.1, (January 1989), pp. 18-25, ISSN 0160-6689

Sheean, G.L. (1991). Lithium Neurotoxicity. Clinical and Experimental Neurology, Vol.28, pp. 112-127, ISSN 0196-6383

Shelton, R.C. (2006). The Nature of the Discontinuation Syndrome Associated with Antidepressant Drugs. Journal of Clinical Psychiatry, Vol.67, Suppl.4, pp. 3-7, ISSN 0160-6689

Shiloh, R., Valevski, A., Bodinger, L., Misgav, S., Aizenberg, D., Dorfman-Etrog, P., Weizman, A. \& Munitz, H. (2003). Precautionary Measures Reduce Risk of Definite Neuroleptic Malignant Syndrome in Newly Typical Neuroleptic-Treated Schizophrenia Inpatients. International Clinical Psychopharmacology, Vol.18, No.3, (May 2003), pp. 147-149, ISSN 0268-1315

Siegel, A.J. (2008). Hyponatremia in Psychiatric Patients: Update on Evaluation and Management. Harvard Review of Psychiatry, Vol.16, No.1, pp. 13-24, ISSN 1067-3229

Singh, A.N. \& MaGuire, J. (1987). Neuroleptic Malignant Syndrome (NMS): A Misnomer? British Journal of Psychiatry, Vol.151, No.6, (December 1987), pp. 863-864

Smith, M., Hopkins, D., Peveler, R.C., Holt, R.I.G., Woodward, M. \& Ismail, K. (2008). First$V$. Second-Generation Antipsychotics and Risk for Diabetes in Schizophrenia: Systematic Review and Meta-Analysis. British Journal of Psychiatry, Vol.192, No.6, (June 2008), pp. 406-411, ISSN 0007-1250

Spigset, O. \& Hedenmalm, K. (1995). Hyponatraemia and the Syndrome of Inappropriate Antidiuretic Hormone Secretion (SIADH) Induced by Psychotropic Drug. Drug Safety, Vol.12, No.3, (March 1995), pp. 209-225, ISSN 0114-5916 
Spirt, M.J., Chan, W., Thieberg, M. \& Sachar, D.B. (1992). Neuroleptic Malignant Syndrome Induced by Domperidone. Digestive Diseases and Sciences, Vol.37, No.6, (June 1992), pp. 946-948, ISSN 0163-2116

Spivak, B., Maline, D.I., Kozyrev, V.N., Mester, R., Neduva, S.A., Ravilov, R.S. \& Weizman, A. (2000). Frequency of Neuroleptic Malignant Syndrome in a Large Psychiatric Hospital in Moscow. European Psychiatry, Vol.15, No.5, (August 2000), pp. 330-333, ISSN 0924-9338

Sporer, K.A. (1995). The Serotonin Syndrome. Implicated Drugs, Pathophysiology and Management. Drug Safety, Vol.13, No.2, (August 1995), pp. 94-104, ISSN 0114-5916

Steele, D., Keltner, N.L. \& McGuiness, T.M. (2011). Are Neuroleptic Malignant Syndrome and Serotonin Syndrome the Same Syndrome? Perspectives in Psychiatric Care, Vol.47, No.1, (January 2011), pp. 58-62, ISSN 0031-5990

Sternbach, H. (1991). The Serotonin Syndrome. American Journal of Psychiatry, Vol.148, No.6, (June 1991), pp. 705-713, ISSN 0002-953X

Sterns, R.H., Nigwekar, S.U. \& Hix, J.K. (2009). The Treatment of Hyponatremia. Seminars in Nephrology, Vol.29, No.3, (May 2009), pp. 282-299, ISSN 0270-9295

Strawn, J.R., Keck, P.E. Jr. \& Caroff, S.N. (2007). Neuroleptic Malignant Syndrome. American Journal of Psychiatry, Vol.164, No.6, (June 2007), pp. 870-876, ISSN 0002-953X

Susman, V.L. (2001). Clinical Management of Neuroleptic Malignant Syndrome. Psychiatric Quarterly, Vol.72, No.4, (December 2001), pp. 325-328, ISSN 0033-2720

Takubo, H., Harada, T., Hashimoto, T., Inaba, Y., Kanazawa, I., Kuno, S., Mizuno, Y., Mizuta, E., Murata, M., Nagatsu, T., Nakamura, S., Yanagisawa, N. \& Narabayashi, H. (2003). A Collaborative Study on the Malignant Syndrome in Parkinson's Disease and Related Disorders. Parkinsonism and Related Disorders, Vol.9, Suppl.1, (April 2003), pp. S31-S41, ISSN 1353-8020

Tamam, L. \& Ozpoyraz, N. (2002). Selective Serotonin Reuptake Inhibitor Discontinuation Syndrome: A Review. Advances in Therapy, Vol.19, No.1, (January/February 2002), pp. 17-26, ISSN 0741-238X

Taylor, N.E. \& Schwartz, H.I. (1988). Neuroleptic Malignant Syndrome Following Amoxapine Overdose. Journal of Nervous and Mental Disease, Vol.176, No.4, (April 1988), pp. 249-251, ISSN 0022-3018

Thomas, Z., Bandali, F., McCowen, K. \& Malhortra, A. (2010). Drug-Induced Endocrine Disorders in the Intensive Care Unit. Critical Care Medicine, Vol.38, No.6, Suppl., (June 2010), pp. S219-S230, ISSN 0090-3493

Toru, M., Matsuda, O., Makiguchi, K. \& Sugano, K. (1981). Neuroleptic Malignant Syndrome-Like State Following a Withdrawal of Antiparkinsonian Drugs. Journal of Nervous and Mental Disease, Vol.169, No.5, (May 1981), pp. 324-327, ISSN 0022-3018

Trollor, J.N. \& Sachdev, P.S. Electroconvulsive Treatment of Neuroleptic Malignant Syndrome: A Review and Report of Cases. Australian and New Zealand Journal of Psychiatry, Vol.33, No.5, (October 1999), pp. 650-659, ISSN 0004-8674

Trollor, J.N., Chen, X. \& Sachdev, P.S. (2009). Neuroleptic Malignant Syndrome Associated with Atypical Antipsychotic Drugs. CNS Drugs, Vol.23, No.6, (June 2009), pp. 477492, ISSN 1172-7047

Upadhyay, A., Jaber, B.L. \& Madias, N.E. (2006). Incidence and Prevalence of Hyponatremia. American Journal of Medicine, Vol.119, No.7, Suppl. 1(July 2006), pp. S30-S35, ISSN 0002-9343 
Upadhyay, A., Jaber, B.L. \& Madias, N.E. (2009). Epidemiology of Hyponatremia. Seminars in Nephrology, Vol.29, No.3, (May 2009), pp. 227-238, ISSN 0270-9295

Velamoor, V.R., Norman, R.M., Caroff, S.N., Mann, S.C., Sullivan, K.A. \& Antelo, R.E. (1994). Progression of Symptoms in Neuroleptic Malignant Syndrome. Journal of Nervous and Mental Disease, Vol.182, No.3, (March 1994), pp. 168-173, ISSN 00223018

Viejo, L.F., Morales, V., Puňal, P., Pérez, J.L. \& Sancho, R.A. (2003). Risk Factors in Neuroleptic Malignant Syndrome. A Case-Control Study. Acta Psychiatrica Scandinavica, Vol.107, No.1, (January 2003), pp. 45-49, ISSN 0001-690X

Vieweg, W.V., David, J.J., Rowe, W.T., Wampler, G.J., Burns, W.J. \& Spradlin, W.W. (1985). Death from Self-Induced Water Intoxication among Patients with Schizophrenic Disorders. Journal of Nervous and Mental Disorders, Vol.173, No.3, (March 1985), pp. 161-165, ISSN 0022-3018

Vieweg, W.V., Rowe, W.T., David, J.J., Curnow, R.T. \& Spradlin, W.W. (1986). Self-Induced Water Intoxication and Psychosis (SIWIP): Subcategory of the Syndrome of Inappropriate Antidiuresis (SIAD). Psychiatric Medicine, Vol.4, No.3, pp. 277-290, ISSN 0732-0868

Watson, W.A., Litovitz, T.L., Rodgers, G.C. Jr., Klein-Schwartz, W., Reid, N., Youniss, J., Flanagan, A. \& Wruk, K.M. (2005). 2004 Annual Report of the American Association of Poison Control Centers Toxic Exposure Surveillance System. American Journal of Emergency Medicine, Vol.23, No.5, (September 2005), pp. 589-666, ISSN 0735-6757

Wehring, H.J., Kelly, D.L., Love, R.C. \& Conley, R.R. (2003). Deaths from Diabetic Ketoacidosis after Long-Term Clozapine Treatment. American Journal of Psychiatry, Vol.160, No.12, (December 2003), pp. 2241-2242, ISSN 0002-953X

White, D.A.C. (1992). Catatonia and the Neuroleptic Malignant Syndrome - A Single Entity? British Journal of Psychiatry, Vol.161, No.4, (October 1992), pp. 558-560, ISSN 00071250

Woodbury, M.M. \& Woodbury, M.A. (1992). Neuroleptic-Induced Catatonia as a Stage in the Progression toward Neuroleptic Malignant Syndrome. Journal of the American Academy of Child and Adolescent Psychiatry, Vol.31, No.6, (November 1992), pp. 11611164, ISSN 0890-8567

Yamawaki, S., Yano, E. \& Uchitomi, Y. (1990). Analysis of 497 Cases of Neuroleptic Malignant Syndrome in Japan. Hiroshima Journal of Anesthesia, Vol.26, No.1, (March 1990), pp. 35-44

Yamawaki, Y. \& Ogawa, N. (1992). Successful Treatment of Levodopa-Induced Neuroleptic Malignant Syndrome (NMS) and Disseminated Intravascular Coagulation (DIC) in a Patient with Parkinson's Disease. Internal Medicine, Vol.31, No.11, (November 1992), pp. 1298-1302, ISSN 0918-2918

Ziegenbein, M., Kropp, S., Hillemacher, T. \& Bleich, S. (2006). Genetic Predisposition to Neuroleptic Malignant Syndrome in Siblings. Annals of Pharmacotherapy, Vol.40, No.3, (March 2006), pp. 574-575, ISSN 1060-0280 


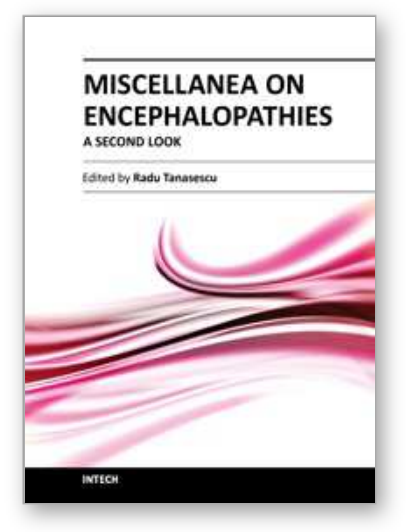

\author{
Miscellanea on Encephalopathies - A Second Look \\ Edited by Dr. Radu Tanasescu
}

ISBN 978-953-51-0558-9

Hard cover, 390 pages

Publisher InTech

Published online 25, April, 2012

Published in print edition April, 2012

The book project "Miscellanea on Encephalopathies-a second look" aims to cover some of the important aspects regarding metabolic, hypoxic, neoplasm- and drug-related encephalopathies, by transmitting valuable information filtered through the real life clinical and research experience of the authors.

\title{
How to reference
}

In order to correctly reference this scholarly work, feel free to copy and paste the following:

Yuji Odagaki (2012). Encephalopathy Associated with Psychotropic Drug Therapy, Miscellanea on Encephalopathies - A Second Look, Dr. Radu Tanasescu (Ed.), ISBN: 978-953-51-0558-9, InTech, Available from: http://www.intechopen.com/books/miscellanea-on-encephalopathies-a-second-look/encephalopathyassociated-with-psychotropic-drug-treatment

\section{INTECH}

open science | open minds

\section{InTech Europe}

University Campus STeP Ri

Slavka Krautzeka 83/A

51000 Rijeka, Croatia

Phone: +385 (51) 770447

Fax: +385 (51) 686166

www.intechopen.com

\section{InTech China}

Unit 405, Office Block, Hotel Equatorial Shanghai

No.65, Yan An Road (West), Shanghai, 200040, China 中国上海市延安西路65号上海国际贵都大饭店办公楼 405 单元

Phone: +86-21-62489820

Fax: $+86-21-62489821$ 
(C) 2012 The Author(s). Licensee IntechOpen. This is an open access article distributed under the terms of the Creative Commons Attribution 3.0 License, which permits unrestricted use, distribution, and reproduction in any medium, provided the original work is properly cited. 